\title{
A Novel Stability Evaluation Technique for Clustering Algorithms in Vehicular Ad Hoc Networks
}

Mohammed Saad Talib ( $\sim$ mohammed.saad@uobabylon.edu.iq)

University of Babylon https://orcid.org/0000-0002-2316-9242

\section{Aslinda Hassan}

Universiti Teknikal Malaysia Melaka

\section{Zuraida Abal Abas}

Universiti Teknikal Malaysia Melaka

\section{Ali A Mohammed}

Technical University of Malaysia Malacca: Universiti Teknikal Malaysia Melaka

\section{Arif Razzaq}

Technical University of Malaysia Malacca Faculty of Information and Communication Technology: Universiti Teknikal Malaysia Melaka Fakulti Teknologi Maklumat dan Komunikasi

\section{Mohanad Faeq Ali}

Technical University of Malaysia Malacca Faculty of Information and Communication Technology: Universiti Teknikal Malaysia Melaka Fakulti Teknologi Maklumat dan Komunikasi

\section{Research Article}

Keywords: Vehicular ad hoc networks, Clustering, Intelligent transport systems, Stability evaluation, Internet of things, Cluster maintenance, Center base clustering

Posted Date: February 18th, 2021

DOl: https://doi.org/10.21203/rs.3.rs-220323/v1

License: (c) (i) This work is licensed under a Creative Commons Attribution 4.0 International License. Read Full License 


\title{
A novel stability evaluation technique for clustering algorithms in vehicular ad hoc networks
}

\author{
Mohammed Saad Talib ${ }^{1,2}$, Aslinda Hassan ${ }^{1}$, Zuraida Abal Abas ${ }^{1}$, Ali A Mohammed ${ }^{1}$, Arif \\ Razzaq $^{1}$, Mohanad Faeq Ali ${ }^{1}$ \\ ${ }^{1}$ Center for Advanced Computing Technology, Faculty of Information and Communication Technology, Universiti \\ Teknikal Malaysia Melaka, Melaka 76100, Malaysia \\ ${ }^{2}$ College of Administration and Economics, University of Babylon, Babylon City 51006, Iraq
}

Corresponding author: Mohammed Saad Talib, Aslinda Hassan

\begin{abstract}
The development of the technology and connected devices such as internet of things (IoT), internet of vehicles ( $\mathrm{IoV}$ ), and $5 \mathrm{G}$ motivate the researchers to give more attention in the field. Clustering is a key factor in vehicular ad-hoc network (VANET) where a number of vehicles join to form a group based on common characteristics. Vehicles are distinguished by their high mobility in ad hoc vehicle networks. Changes frequently occur in the topology of VANET, causing continuous failures in network communication. In such a dynamic environment, the creation and maintenance of a stable cluster are significant challenges. The evaluation of stability in VANET clustering is an important part to evaluate the clustering approaches. In this paper, a mathematical technique (based on the birth-death process) is created to evaluate the clusters stability based on the number of leaving and joining vehicles to each cluster after its creation. The stability of the created clusters is tested by checking the number of vehicles in each cluster at different successive times. These tests indicate the joining and leaving vehicles to each cluster and their effects on the cluster stability. When the results of the technique show that the standard deviation is small for each cluster, it can be concluded that the proposed clustering algorithm is able to achieve stability in cluster maintaining phase.
\end{abstract}

Keyword: Vehicular ad hoc networks, Clustering, Intelligent transport systems, Stability evaluation, Internet of things, Cluster maintenance, Center base clustering.

\section{Introduction}

Intelligent Transportation Systems (ITS) and internet of things (IoT) technologies have been built dramatically in recent years. Various models have been proposed and implemented in support of this technology [1]. This varies from the level of network elements such as the routing, clustering, reliability analysis, congestion solutions, Internet of vehicles (IoV) [2]. Wireless access in vehicular environments (WAVE) is used on dedicated short-range communications (DSRC) [3] frequency bands by IEEE802.11P for vehicular ad hoc networks (VANET) wireless communication. DSRC is currently used to meet the requirement of a low latency for vehicle to vehicle communication (V2V) control messages, and safety, also long term 
evolution (LTE) [4] is used for vehicle to infrastructure communication (V2I). Each vehicle actions as a mobile router, and it used available sensor in each vehicle called on-board unit (OBU) to communicate with the nearby vehicles, and roadside units within a coverage [5]. The mobile ad hoc network (MANET) methods have been adopted by several VANET approaches, as there are some similar features [6]. However, VANET has its own distinctive characteristics, such as high mobility of vehicles. In different applications, clustering in VANETs is fundamental. It has been used by some researchers to build a data-dissemination method to avoid flooding in the network based on different approaches. Figure 1 illustrates the clustering in VANET.

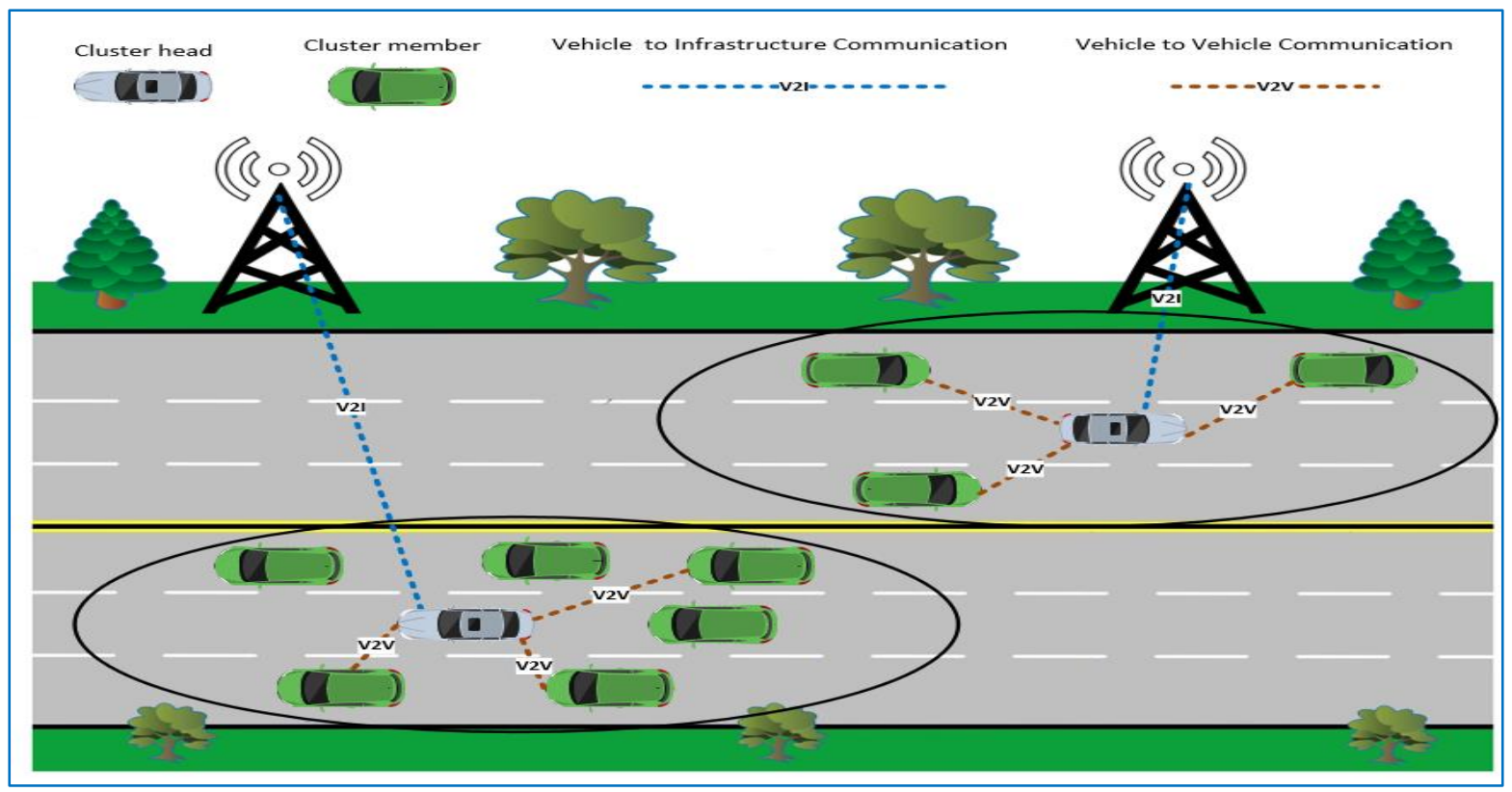

Figure 1: Clustering in vehicular ad hoc networks

VANET clustering is considered to be a critical method for boosting a network performance. More than one aspect is associated with it. Stable clustering, for example, is reflected in good MAC scheduling performance, efficient routing, and a reliable and stable network as a result. Clustering has many categories and types in VANET, such as topology single-hop and multi-hop [7]. The clustering contains of three phases, the first phase is creating creation, the second phase is cluster head selection, and the third phase is cluster maintenance.

Many approaches have been proposed for VANET clustering. However, most of them focused on the cluster head selection and give less attention to the other phases. The high dynamic of the VANET environment making the creation and maintenance of stable clusters is a big challenge issue. The stability of clusters is a key factor in VANET clustering. Several approaches have 
been proposed to develop the clustering algorithms for increasing the stability [8]. This article aims to tackle the complexity of the stability evaluation in VANETs clustering. More specifically, this paper focused on utilize the calculation of leaving and joining vehicles from/to cluster during the maintenance phase to evaluate the stability of the clustering, to solve certain challenging issues in stability evaluation in VANET clustering such as the complex calculations

of the performance metrics, and applying these metrics to other algorithms to comparing the algorithms and then show the superiority. This paper proposed a novel VANET clustering stability evaluation technique by exploiting the model of the birth-death process based on the leaving and joining vehicles in the maintenance phase. The contributions of this article can be summarized as follows:

- This article proposed a novel technique to evaluate cluster stability.

- It has developed the birth-death process model for the cluster maintenance phase.

- This article employs a mathematical aspect to utilize in the dynamic environment and different generated scenarios using different parameters including vehicle density and high mobility of vehicles on the highway.

- It extensively evaluates based on the joining and leaving vehicles to/from each cluster.

The article is organized as follows. The literature is provided in section 2. Next, the methodology of the proposed technique is presented in section 3. After that, experimental results and discussion are presented in section 4. Finally, the conclusion with the future work is given in section 5 .

\section{Related works}

The evaluation of VANETs clustering approaches concentrates on the stability of the generated clusters. More specifically, the further prolonged state of the vehicle in terms of cluster head $(\mathrm{CH})$ or cluster member $(\mathrm{CM})$ can be used as clustering performance metrics; these are known as cluster head lifetime and cluster member lifetime, respectively. Another aspect of performance is the clustering efficiency. This metrics provide the effectiveness of the clustering approach. Connecting these metrics to other performance aspects, such as the number of clusters, which need to be reduced, can present a broader view of stability and effectiveness [9] [10] [11] [12]. The evaluation of the clustering stability is based on performance metrics such as efficiency, average cluster head duration (CHD), average cluster member duration (CMD), average cluster head change rate (CHCR), and number of clusters which need complex computations. Moreover, 
these metrics need to compare the presented approaches with other relevant approaches to show the superiority. Figure 2 shows the performance metrics of clustering in vehicular ad hoc networks.

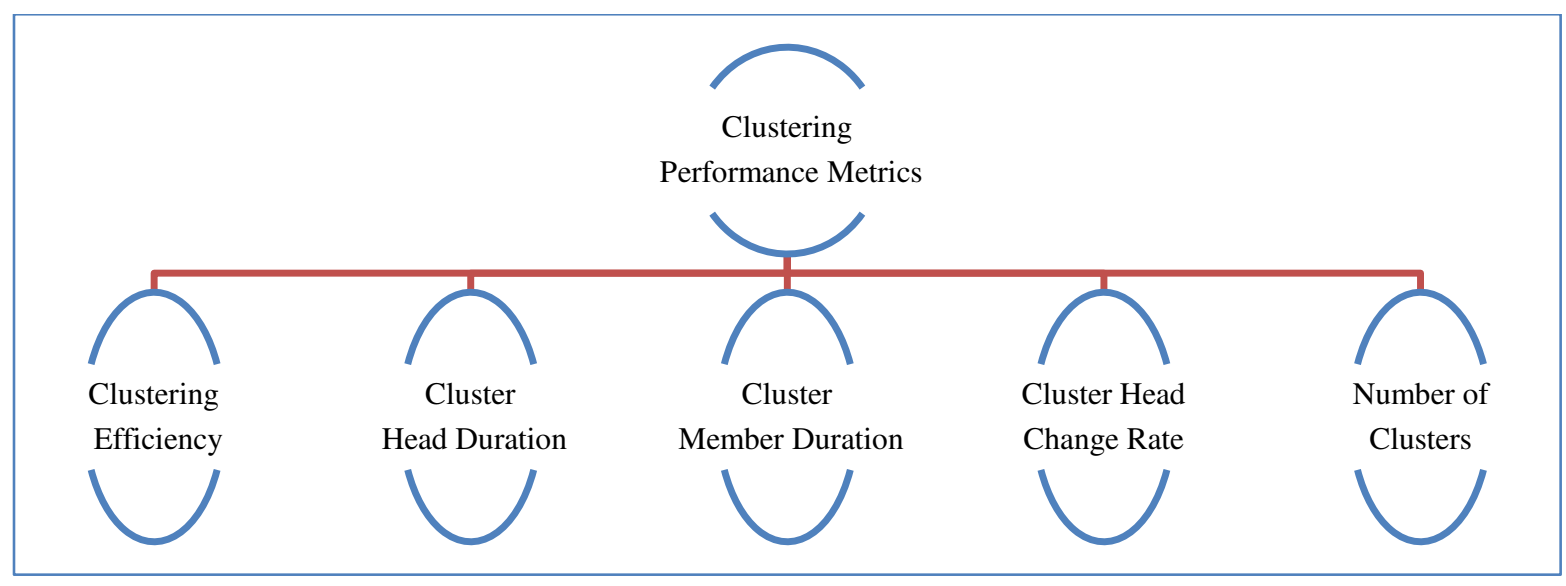

Figure 2: Performance metrics of clustering stability

Clustering efficiency: The percentage of vehicles entering the clustering phase in the simulation is the metric of clustering efficiency. Dividing the number of vehicles that were part of the cluster (cluster member or cluster head) into the total number of vehicles is determined.

Average cluster head duration: The time from changing the state of a vehicle as cluster head to a time when this vehicle leaves this state is called cluster head duration. The average $\mathrm{CH}$ duration (ACHD) is estimated by dividing the total cluster head duration periods to the number of state changes. The average length of the cluster head shows the average duration of being in the state of the cluster head. The longer $\mathrm{CH}$ lifetime is an indicator of the high stability of the clustering approach.

Average cluster member duration: Vehicle cluster member duration represents the time interval from joining the cluster as a cluster member to leaving this cluster by changing its state. A measure of the stability in the clustering approach is the average cluster member lifetime or duration (ACMD). It refers to the average time in a CM's state of being. Thus, for each conversion to a member of the cluster, the ACMD is dividing the total time durations over the total number of changes to a cluster member state. This study goal is to maximize the cluster member duration (lifetime).

Average cluster head change rate: Cluster head change rate represents a metric to demonstrate the cluster stability. It is defined as the number of changes from a $\mathrm{CH}$ state to another state 
within a time unit. The average cluster head change rate (ACHCR) is calculated by dividing the total number of changes over the total simulation time.

Number of clusters: During the entire life of the network, the average number of clusters determines how many clusters have been derived from the clustering algorithm. Each simulation experiment resulted certain number of clusters. The average number of clusters is estimated by dividing the total number of the generated clusters in all the experiments by the total number of the simulation experiments. The aim is to reduce the number of clusters. Table 1: Analysis for the most related VANET's clustering approaches.

Table 1: Analysis of clustering approaches

\begin{tabular}{|c|c|c|c|c|c|c|c|}
\hline $\begin{array}{l}\text { Clustering } \\
\text { Approach }\end{array}$ & $\begin{array}{l}\text { Proposed } \\
\text { for }\end{array}$ & $\begin{array}{c}\text { Single } \\
\text { hop }\end{array}$ & $\begin{array}{l}\text { Multi- } \\
\text { hop }\end{array}$ & Simulation & Scenario & Performance metric & Reference \\
\hline ALM & VANETs & --- & --- & $\begin{array}{l}\text { SUMO / } \\
\text { SMURPH }\end{array}$ & Random & $\begin{array}{l}\text { Cluster lifetime, } \\
\text { Status changes }\end{array}$ & [13] \\
\hline GDMAC & MANETs & yes & no & NS2 & Random & $\begin{array}{l}\text { Cluster lifetime, residence } \\
\text { time, status changes }\end{array}$ & {$[14]$} \\
\hline UFLCS & VANETs & no & yes & $\begin{array}{l}\text { iTETRIS, } \\
\text { Octave }\end{array}$ & Random & $\begin{array}{c}\text { Cluster head lifetime, } \\
\text { Cluster head stability, no. of } \\
\text { clusters }\end{array}$ & [15] \\
\hline MBDF & VANETs & --- & --- & $\begin{array}{l}\text { NS3 \& } \\
\text { SUMO }\end{array}$ & Random & Stability, ACMD & [16] \\
\hline $\begin{array}{c}\text { MC- } \\
\text { DRIVE }\end{array}$ & VANETs & --- & --- & NCTUns & Urban & $\begin{array}{c}\text { Overhead, no. of Cluster } \\
\text { head, accuracy }\end{array}$ & [17] \\
\hline LBC & VANETs & yes & No & NS3 & Urban & Cluster head changes & {$[18]$} \\
\hline DBC & VANETs & --- & --- & $\begin{array}{c}\text { JiST/ } \\
\text { SWANS\& } \\
\text { VanetMobiSim }\end{array}$ & Urban & $\begin{array}{c}\text { AC size, A no. of } \mathrm{C}, \mathrm{ACH}, \mathrm{A} \\
\text { no. of } \mathrm{CHCh} \text {, efficiency }\end{array}$ & [19] \\
\hline $\mathrm{CA}$ & VANETs & no & yes & --- & Urban & $\begin{array}{c}\text { Lifetime, throughput, } \\
\text { overhead }\end{array}$ & [20] \\
\hline MDMAC & VANETs & no & yes & Jist/SWANS++ & Urban & Overhead, no. of clusters & {$[21]$} \\
\hline DMSC & VANETs & yes & no & $\begin{array}{l}\text { ns-2 \& } \\
\text { SUMO }\end{array}$ & Urban & $\begin{array}{l}\text { CHD, CMD, CHCR, no. of } \\
\text { clusters }\end{array}$ & [12] \\
\hline AMACAD & VANETs & yes & no & $\begin{array}{c}\text { Java } \\
\text { JDeveloper }\end{array}$ & Urban & $\begin{array}{l}\text { CHD, CMD, no. of clusters, } \\
\text { re-affiliation rate }\end{array}$ & [22] \\
\hline
\end{tabular}




\begin{tabular}{|c|c|c|c|c|c|c|c|}
\hline $\begin{array}{l}\text { Clustering } \\
\text { Approach }\end{array}$ & $\begin{array}{l}\text { Proposed } \\
\text { for }\end{array}$ & $\begin{array}{c}\text { Single } \\
\text { hop }\end{array}$ & $\begin{array}{l}\text { Multi- } \\
\text { hop }\end{array}$ & Simulation & Scenario & Performance metric & Reference \\
\hline & & & & $10 \mathrm{G}$ & & & \\
\hline VWCA & VANETs & --- & --- & MATLAB & Highway & ACHD, ACMD & {$[23]$} \\
\hline CCA & VANETs & no & yes & SUMO & $\begin{array}{c}\text { high } \\
\text { mobility }\end{array}$ & $\begin{array}{c}\text { Lifetime, no. of clusters, } \\
\text { ACHCR, ACMCR }\end{array}$ & {$[24]$} \\
\hline SBCA & VANETs & yes & no & ns-2 & Highway & AC lifetime, overhead, PDR & {$[25]$} \\
\hline TBC & VANETs & yes & yes & $\mathrm{C}++$ & Highway & $\begin{array}{c}\text { Cluster stability, AC } \\
\text { lifetime, no. of clusters }\end{array}$ & [26] \\
\hline $\mathrm{Sp}-\mathrm{CI}$ & VANETs & yes & yes & --- & Highway & $\begin{array}{l}\text { Cluster stability, no. of } \\
\text { clusters, Cluster lifetime }\end{array}$ & {$[27]$} \\
\hline FLBA & VANETs & yes & no & $\begin{array}{l}\text { ns-2, MOVE, } \\
\text { SUMO }\end{array}$ & Highway & $\mathrm{CHD}, \mathrm{CMD}, \mathrm{AC}$ size & [28] \\
\hline APROVE & VANETs & yes & no & ns-2 & Highway & $\begin{array}{c}\text { ACHD, ACMD, ACHCR, A } \\
\text { no. of clusters }\end{array}$ & [9] \\
\hline $\begin{array}{l}\text { MCTC } \\
\text { MDC }\end{array}$ & VANETs & yes & no & MATLAB & Highway & $\begin{array}{c}\text { AC lifetime, AC size } \\
\text { A no. of } \mathrm{CHs}\end{array}$ & [29] \\
\hline DMCNF & VANETs & no & yes & $\begin{array}{c}\text { ns-2/ } \\
\text { VanetMobiSim }\end{array}$ & $\begin{array}{l}\text { High- } \\
\text { mobility }\end{array}$ & $\begin{array}{l}\text { CHD, CMD, CHCR, no. of } \\
\text { clusters }\end{array}$ & [10] \\
\hline $\begin{array}{l}\text { VMaSC- } \\
\text { LTE }\end{array}$ & VANETs & no & yes & $\begin{array}{l}\text { NS3 \& } \\
\text { SUMO }\end{array}$ & Highway & $\begin{array}{c}\text { CHD, CMD, CHCR, } \\
\text { Overhead }\end{array}$ & [11] \\
\hline CBSC & VANETs & --- & --- & $\begin{array}{l}\text { OMNeT++ \& } \\
\text { SUMO }\end{array}$ & Highway & $\begin{array}{l}\text { ACMD, A no. of re- } \\
\text { affiliation, PLR }\end{array}$ & [30] \\
\hline UFC & VANETs & yes & no & SUMO & Highway & $\begin{array}{l}\text { CHD, CMD, no. of clusters, } \\
\text { Efficiency }\end{array}$ & [31] \\
\hline CBSC & VANETs & yes & no & Veins LTE & Highway & ACHD, ACMD, PLR & {$[32]$} \\
\hline $\begin{array}{l}\text { DBSCAN- } \\
\text { FLC }\end{array}$ & VANETs & yes & no & $\begin{array}{l}\text { MATLAB } \\
\text { R2017b }\end{array}$ & Highway & $\begin{array}{c}\mathrm{ACD}, \text { vehicle status change, } \\
\text { no. of clusters }\end{array}$ & [33] \\
\hline
\end{tabular}

\section{Methodology}

Usually, vehicles inside each cluster move at different speeds. The number of vehicles in each cluster may increases, decrease, or stay without change after a certain time interval. As the number of vehicles in a cluster remains without modification for a long-time-interval, this gives a good indication for improving cluster stability. The next system state will have decreased, increased, or stay without change during a very short interval. These processes are based on a 
stochastic process (called the Birth-Death process). Each cluster can lose a vehicle (according to a leaving process) due to either it has a higher acceleration/speed, or it may have a very low acceleration/speed (the vehicles number in a cluster will be decreased; which is equivalent to a death process).

A cluster can get an additional vehicle (as a joining vehicle) that either has a very high speed to leave forward from a back cluster or it may have a very slow to lag from a forward (leading) cluster (the vehicles number in a cluster will be increased by one; which is equivalent to a birth process). All these cases can happen with certain probabilities based on the vehicle acceleration and speed. Figure 3 represents a schematic diagram to show these possible cases, while Figure 4 presents a developed flowchart to indicate the vehicles leaving and joining possibilities.

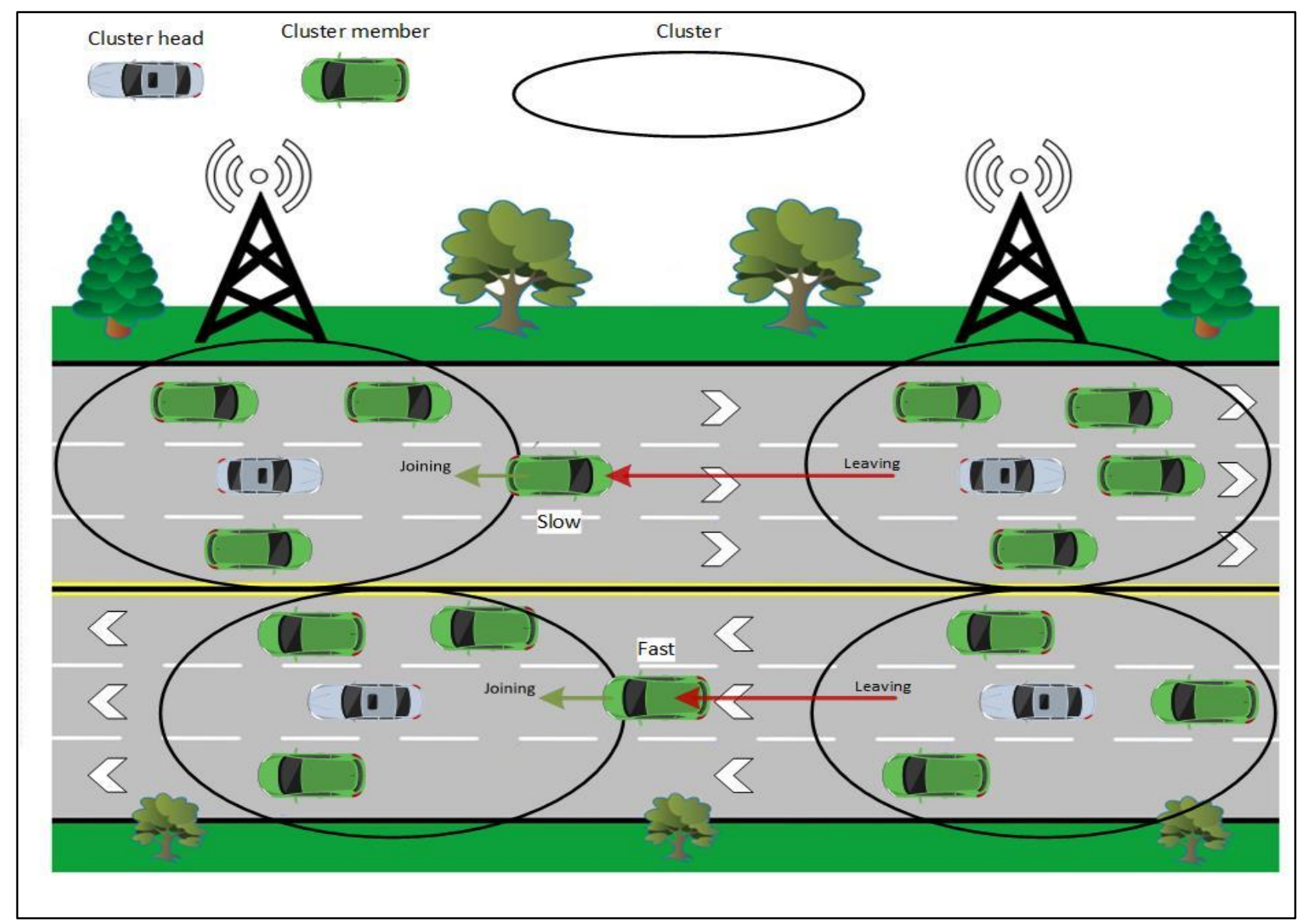

Figure 3: Vehicles leaving and joining representation 


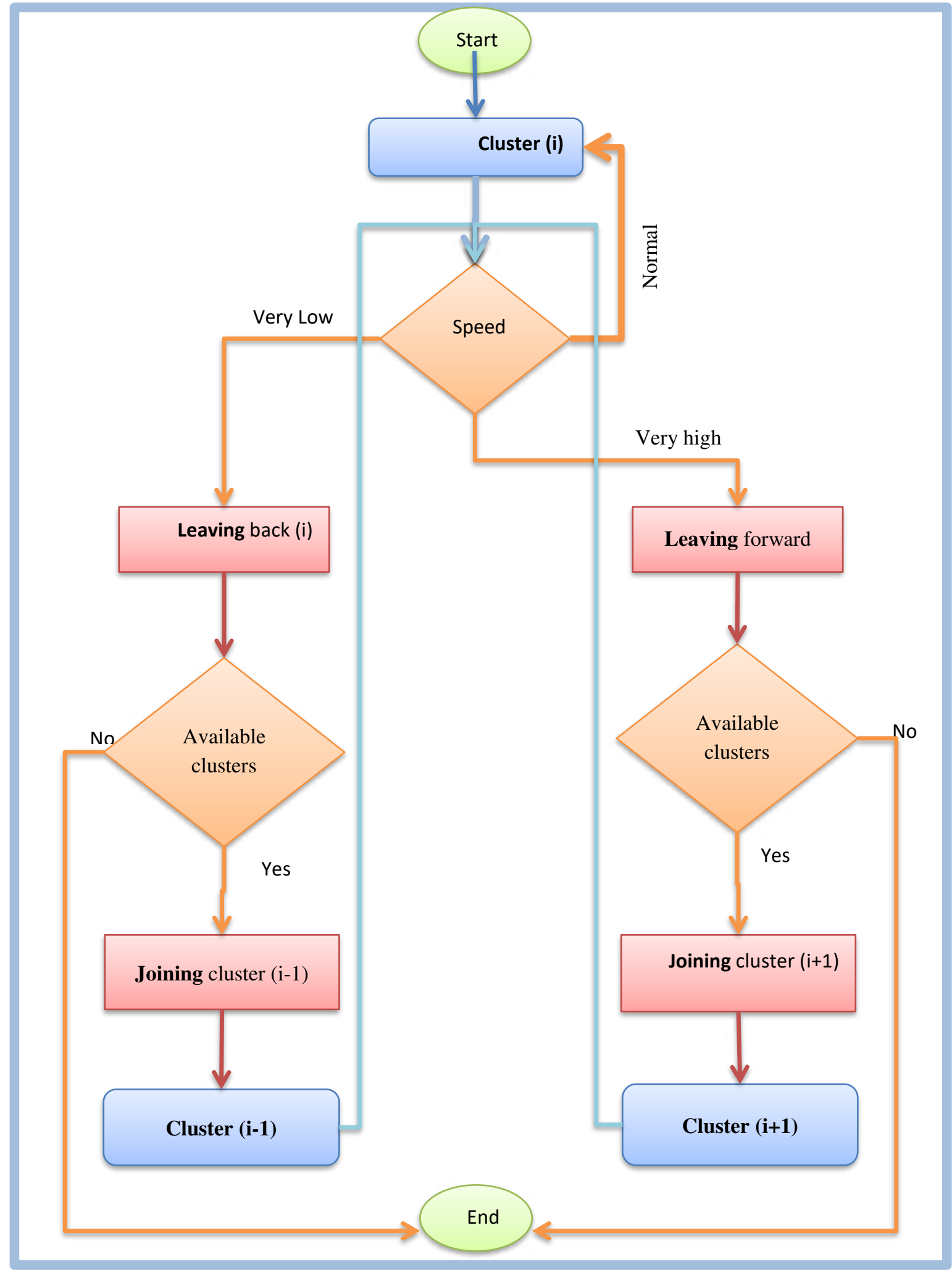

Figure 4: Flowchart for vehicles leaving and joining from/to a cluster 
Based on Figure 3, the following assumptions can be suggested:

$\Delta \mathrm{t}$ : very short interval of time.

$\mathrm{n}$ : numbers of vehicles in the zone area at the time $\mathrm{t}$.

Lf: leaving rate (vehicle leave its cluster forward; very fast; v. high speed).

$\mathrm{L}_{\mathrm{b}}$ : leaving rate (vehicle leave its cluster backward; very slow; v. low speed).

$\mathrm{J}_{\mathrm{f}}$ : joining rate (vehicle joining a cluster from forward; very slow; $\mathrm{v}$. low speed).

$\mathrm{J}_{\mathrm{b}}$ : joining rate (vehicle joining a cluster from backward; very fast; $\mathrm{v}$. high speed).

S: vehicle staying in its cluster.

$E_{n}$ : the system's state means (vehicles number in a cluster at a certain time).

$\mathrm{O}(\Delta \mathrm{t}):(\operatorname{order} \Delta \mathrm{t})=0$.

$\mathrm{t}:$ is the current time.

$\mathrm{t}+\Delta \mathrm{t}$ : is the next time or after a period of $\Delta \mathrm{t}$.

$\mathrm{P}_{\mathrm{n}}(\mathrm{t})=$ probability that there are $\mathrm{n}$ vehicles in the cluster at time $\mathrm{t}$.

$\mathrm{P}_{\mathrm{n}}(\mathrm{t}, \mathrm{t}+\Delta \mathrm{t})=$ probability that there are $\mathrm{n}$ vehicles in a cluster at time $(\mathrm{t}+\Delta \mathrm{t})$.

Any joining process can be modelled as the birth process.

Any leaving process can be modelled as the death process.

The whole problem can be modelled as a complex birth-death process.

1. The probability that a vehicle leaves its cluster forward in an interval of time $(\mathrm{t}, \mathrm{t}+\Delta \mathrm{t})$; thus $\Delta \mathrm{t}$ is a very short interval of time, and the system having $\mathrm{n}$ vehicles $\left(E_{n}\right)$ is:

Pr. one vehicle will leave forward in $(t, t+\Delta t)$, and the system is in state $E_{n}$ 


$$
=\mathrm{L}_{\mathrm{f}} \Delta \mathrm{t}+\mathrm{O}(\Delta \mathrm{t})
$$

2. The probability that a vehicle leaves its cluster backward in the interval of time $(\mathrm{t}, \mathrm{t}+\Delta \mathrm{t})$; thus $\Delta \mathrm{t}$ is a very short interval of time, and the system having $\mathrm{n}$ vehicles $\left(E_{n}\right)$ is:

Pr. one vehicle will leave backward in: $t, t+\Delta t$ and the system is in state $E_{n}$ :

$$
=\mathrm{L}_{b} \Delta \mathrm{t}+\mathrm{O}(\Delta \mathrm{t})
$$

3. The probability that a vehicle joining a cluster from its head in the interval of time $(\mathrm{t}, \mathrm{t}+\Delta \mathrm{t})$; thus, $\Delta \mathrm{t}$ is a very short interval of time, and the system having $\mathrm{n}$ vehicles $\left(E_{n}\right)$ is:

Pr. one vehicle will join from forward in: $t, t+\Delta t$ and the system is in state $E_{n}$

$$
=\mathrm{J}_{\mathrm{f}} \Delta \mathrm{t}+\mathrm{O}(\Delta \mathrm{t})
$$

4. The probability that a vehicle joining a cluster from back in the interval of time $(\mathrm{t}, \mathrm{t}+\Delta \mathrm{t})$; thus $\Delta \mathrm{t}$ is a very short interval of time, and the system having $\mathrm{n}$ vehicles $\left(E_{n}\right)$ is:

Pr. one vehicle will join from back in: $t, t+\Delta t$ and the system is in state $E_{n}$

$$
=\mathrm{J}_{\mathrm{b}} \Delta \mathrm{t}+\mathrm{O}(\Delta \mathrm{t})
$$

5. The probability that no vehicle leaves or joins its cluster backward or forward in the interval of time $(\mathrm{t}, \mathrm{t}+\Delta \mathrm{t})$

Pr. no vehicle leaves or joins its cluster backward or forward in: $\mathrm{t}, \mathrm{t}+\Delta \mathrm{t}$ and the system is in state $E_{n}:$

$$
=\left(1-\mathrm{L}_{\mathrm{b}} \Delta \mathrm{t}\right)\left(1-\mathrm{L}_{\mathrm{f}} \Delta \mathrm{t}\right)\left(1-\mathrm{J}_{\mathrm{b}} \Delta \mathrm{t}\right)\left(1-\mathrm{J}_{\mathrm{f}} \Delta \mathrm{t}\right)+\mathrm{O}(\Delta \mathrm{t})
$$

6. The forward leaving the state and backward leaving the state are independent of each other.

7. The probability of occurrence of more than one event in the interval of time $(t, t+\Delta t)$ is equal to zero, thus:

Pr. more than one event in: $\mathrm{t}, \mathrm{t}+\Delta \mathrm{t}=\mathrm{O}(\Delta \mathrm{t})$ 
This paper assumes that $p_{n}(t)$ is the probability of being the system in state $E_{n}$ (the expected vehicles number in the cluster is $n$ ) at time $t$, or the probability of being the number of vehicles equal to $(n)$ at time $t$.

Also, $p_{n}(\mathrm{t}, \mathrm{t}+\Delta \mathrm{t})$ is the probability of being the system in state $\mathrm{E}_{\mathrm{n}}$ at the time $(\mathrm{t}, \mathrm{t}+\Delta \mathrm{t})$.

Hence, the possible states at the time $(\mathrm{t}, \mathrm{t}+\Delta \mathrm{t})$ are as follows:

Table 2 summarizes all the expected states at time $\mathrm{t}$ and the possible states at time $\mathrm{t}+\Delta \mathrm{t}$ with all their probabilities and transition possibilities.

Table 2: Expected states at time $\mathrm{t}$ and $\mathrm{t}+\Delta \mathrm{t}$ with all their transitions possibilities

\begin{tabular}{|c|c|c|}
\hline \multirow{2}{*}{ An occurrence at a time $(\mathrm{t}, \mathrm{t}+\Delta \mathrm{t})$} & The Probability & $\begin{array}{c}\text { Transitions from } \\
\text { state at time } \mathrm{t} \text { to state at } \\
\text { time } \mathrm{t}+\Delta \mathrm{t}\end{array}$ \\
\hline No vehicle leaves or joins its cluster & $\left(1-\mathrm{L}_{\mathrm{b}} \Delta \mathrm{t}\right)\left(1-\mathrm{L}_{\mathrm{f}} \Delta \mathrm{t}\right)\left(1-\mathrm{J}_{\mathrm{b}} \Delta \mathrm{t}\right)\left(1-\mathrm{J}_{\mathrm{f}} \Delta \mathrm{t}\right)+\mathrm{O}(\Delta \mathrm{t})$ & $E_{n}$ \\
\hline Only one vehicle will leave forward & $\mathrm{L}_{\mathrm{f}} \Delta \mathrm{t}\left(1-\mathrm{L}_{\mathrm{b}} \Delta \mathrm{t}\right)\left(1-\mathrm{J}_{\mathrm{b}} \Delta \mathrm{t}\right)\left(1-\mathrm{J}_{\mathrm{f}} \Delta \mathrm{t}\right)+\mathrm{O}(\Delta \mathrm{t})$ & $E_{n+1}$ \\
\hline Only one vehicle will leave backward & $\mathrm{L}_{\mathrm{b}} \Delta \mathrm{t}\left(1-\mathrm{L}_{\mathrm{f}} \Delta \mathrm{t}\right)\left(1-\mathrm{J}_{\mathrm{b}} \Delta \mathrm{t}\right)\left(1-\mathrm{J}_{\mathrm{f}} \Delta \mathrm{t}\right)+\mathrm{O}(\Delta \mathrm{t})$ & $E_{n+1}$ \\
\hline Only one vehicle will join from forward & $\mathrm{J}_{\mathrm{f}} \Delta \mathrm{t}\left(1-\mathrm{L}_{\mathrm{b}} \Delta \mathrm{t}\right)\left(1-\mathrm{L}_{\mathrm{f}} \Delta \mathrm{t}\right)\left(1-\mathrm{J}_{\mathrm{b}} \Delta \mathrm{t}\right)+\mathrm{O}(\Delta \mathrm{t})$ & $E_{n-1}$ \\
\hline Only one vehicle will join from backward & $\mathrm{J}_{\mathrm{b}} \Delta \mathrm{t}\left(1-\mathrm{L}_{\mathrm{b}} \Delta \mathrm{t}\right)\left(1-\mathrm{L}_{\mathrm{f}} \Delta \mathrm{t}\right)\left(1-\mathrm{J}_{\mathrm{f}} \Delta \mathrm{t}\right)+\mathrm{O}(\Delta \mathrm{t})$ & $E_{n-1}$ \\
\hline More than one occurrence & $\mathrm{O}(\Delta \mathrm{t})$ & $E_{n}$ \\
\hline
\end{tabular}

Equation (3.24) can be derived by collecting Equations (3.18) to (3.23) with Table 3.10.

$$
\begin{gathered}
\mathrm{P}_{\mathrm{n}}(\mathrm{t}, \mathrm{t}+\Delta \mathrm{t})=\mathrm{P}_{\mathrm{n}}(\mathrm{t})\left(1-\mathrm{L}_{\mathrm{b}} \Delta \mathrm{t}\right)\left(1-\mathrm{L}_{\mathrm{f}} \Delta \mathrm{t}\right)\left(1-\mathrm{J}_{\mathrm{b}} \Delta \mathrm{t}\right)\left(1-\mathrm{J}_{\mathrm{f}} \Delta \mathrm{t}\right)+\mathrm{P}_{\mathrm{n}+1}(\mathrm{t}) \mathrm{L}_{\mathrm{f}} \Delta \mathrm{t}\left(1-\mathrm{L}_{\mathrm{b}} \Delta \mathrm{t}\right)\left(1-\mathrm{J}_{\mathrm{b}} \Delta \mathrm{t}\right)(1- \\
\left.\mathrm{J}_{\mathrm{f}} \Delta \mathrm{t}\right)+\mathrm{P}_{\mathrm{n}+1}(\mathrm{t}) \mathrm{L}_{\mathrm{b}} \Delta \mathrm{t}\left(1-\mathrm{L}_{\mathrm{f}} \Delta \mathrm{t}\right)\left(1-\mathrm{J}_{\mathrm{b}} \Delta \mathrm{t}\right)\left(1-\mathrm{J}_{\mathrm{f}} \Delta \mathrm{t}\right)+\mathrm{P}_{\mathrm{n}-1}(\mathrm{t}) \mathrm{J}_{\mathrm{f}} \Delta \mathrm{t}\left(1-\mathrm{L}_{\mathrm{b}} \Delta \mathrm{t}\right)\left(1-\mathrm{L}_{\mathrm{f}} \Delta \mathrm{t}\right)\left(1-\mathrm{J}_{\mathrm{b}}\right. \\
\Delta \mathrm{t})+\mathrm{P}_{\mathrm{n}-1}(\mathrm{t}) \mathrm{J}_{\mathrm{b}} \Delta \mathrm{t}\left(1-\mathrm{L}_{\mathrm{b}} \Delta \mathrm{t}\right)\left(1-\mathrm{L}_{\mathrm{f}} \Delta \mathrm{t}\right)\left(1-\mathrm{J}_{\mathrm{f}} \Delta \mathrm{t}\right)+\mathrm{O}(\Delta \mathrm{t})
\end{gathered}
$$

Equation (7) can be used in expecting the number of vehicles in each cluster at any time. Also, this expectation can be utilized to compare the number of vehicles in any successive times to indicate the increase or reduction. Figure 5 represents the state diagram for vehicles leaving and joining process [34]. 


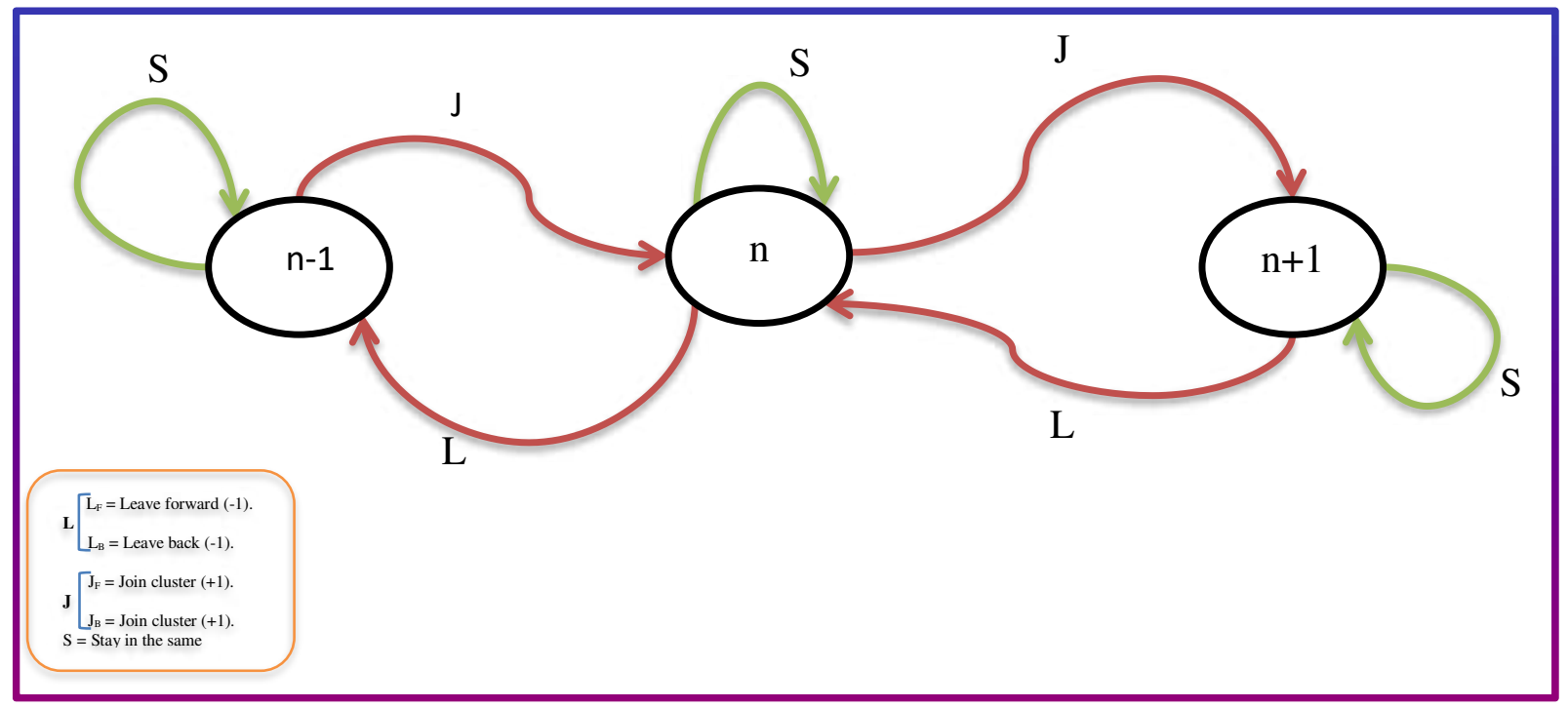

Figure 5: State diagram for vehicles leaving and joining process

\section{Simulation parameters}

The simulation parameters is provided in Table 3 .

Table 3: The simulation parameters of the performed experiments

\begin{tabular}{|c|c|}
\hline Parameter & Value \\
\hline Number of Lanes & $4,6,8$ \\
\hline Experiment Duration & $300 \mathrm{~s}$ \\
\hline Max-Velocity & $30 \mathrm{~m} / \mathrm{s}$ \\
\hline Min-Velocity & $10 \mathrm{~m} / \mathrm{s}$ \\
\hline Transmission Range (TR) & $300 \mathrm{~m}$ \\
\hline Number of Vehicles & $120,200,300$ \\
\hline Length of Environment & $10 \mathrm{~km}$ \\
\hline
\end{tabular}

\section{Results and discussions}

The leaving and joining vehicles to each cluster after its establishment can be expected and observed. In this paper, the concept of this developed technique is implemented to test the stability of the cluster. This technique is used to test the cluster stability by observing the number of vehicles in each cluster at different successive times. All the generated clusters in the proposed approach called CEC-GP [35] are tested at their starting time to indicate the initial number of vehicles. Also, these clusters are tested at different successive times to observe the leaving or the joining vehicles. Five clusters observations are selected randomly from each traffic level and presented as a sample. Figure 6 presents the average number of 
the generated clusters in each traffic level. The number of leaving or joining vehicles to a cluster is observed after each very short time interval $\Delta \mathrm{t}$. These times are; $\mathrm{t}+\Delta \mathrm{t}, \mathrm{t}+2 \Delta \mathrm{t}$, $\mathrm{t}+3 \Delta \mathrm{t}$, and so on). In each of these times, the number of vehicles in a cluster is observed and compared with the previously observed number to indicate any joining or leaving vehicle.

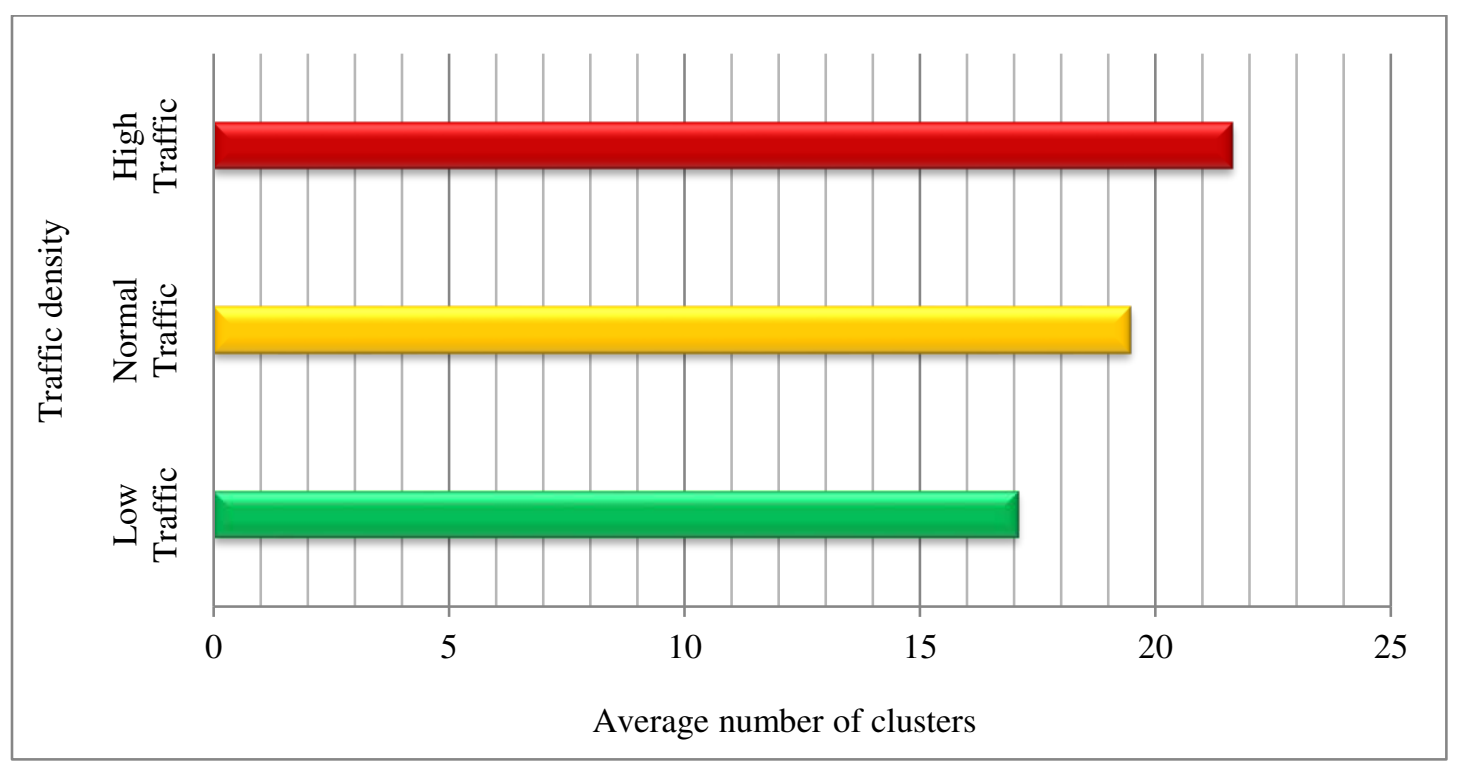

Figure 6: The average number of clusters in CEC-GP

Three possible outcomes can be observed; if the current number is greater than the previous number (there is a joining vehicle to a cluster), if the current number is less than the previous number (there is a leaving vehicle from a cluster), and if the current number is the same with the previous number (there is no joining nor leaving vehicle). The cluster stability is achieved if the cluster size is changed slightly along a certain time.

The cluster is stable when the number of vehicles at each time is close with the average number of vehicles in a cluster. The range measure is used to indicate the difference between the extreme values in each cluster. Keeping these extreme points close will result in a stable cluster. Mean, and standard deviation are also used as statistical indications to measure the central tendency and the spread. This test is implemented in low, medium, and high traffic levels. Table 4 shows the observed number of vehicles in each cluster of CEC-GP on a low traffic level. It presents the observed number of vehicles in each cluster at each time interval $\Delta t$ during the time $\mathrm{t}$ to time $(\mathrm{t}+9 \Delta \mathrm{t})$. A little variation in the number of vehicles in each cluster is observed from the values of the mean, standard deviation, and the range for each cluster. 
Table 4: Number of vehicles in each cluster at each time interval in low traffic level

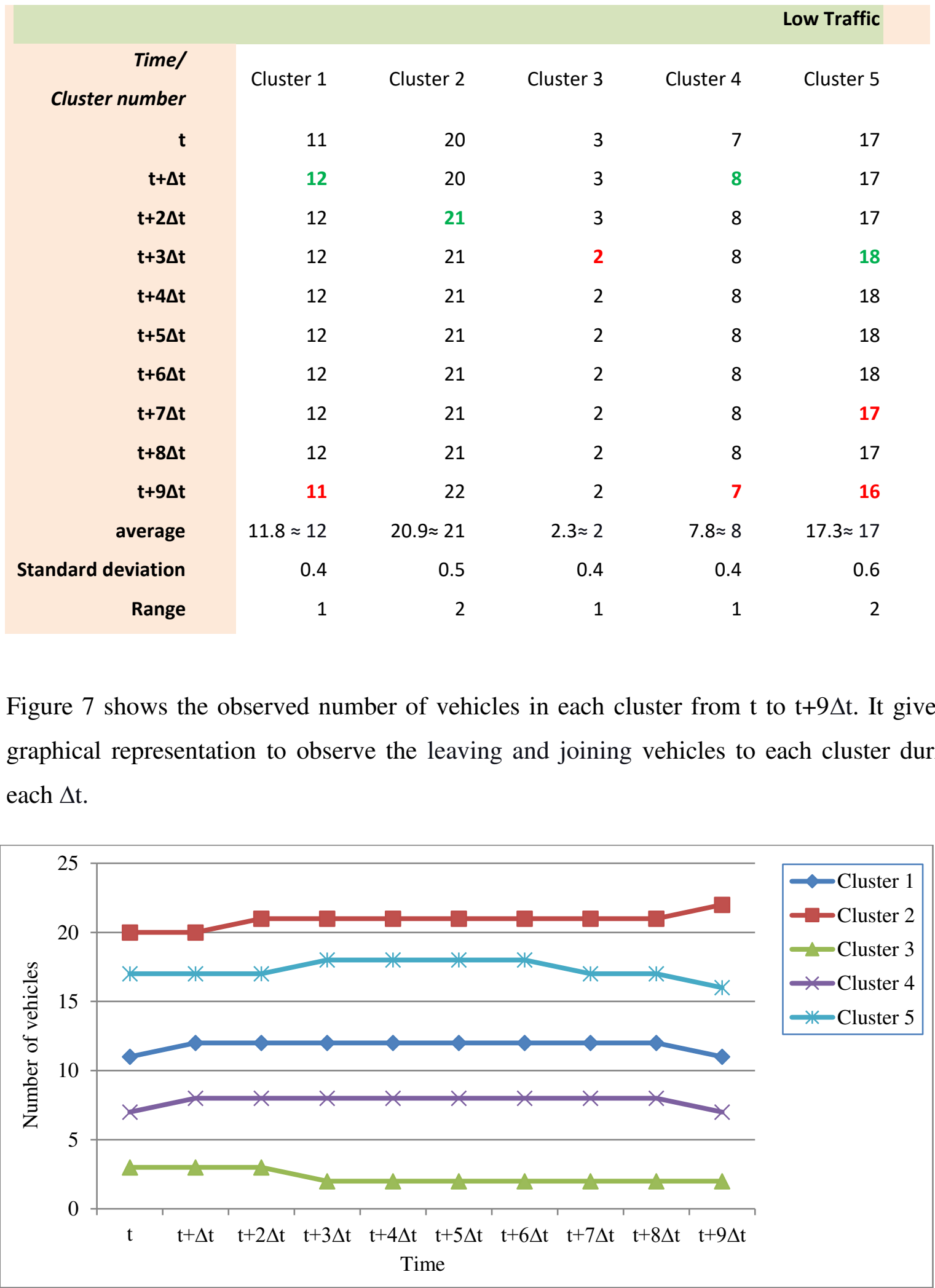

Figure 7: Number of vehicles in each cluster at each time interval for the low traffic level 
Table 5 shows the observed number of vehicles in each cluster in a normal traffic level during the time $t$ to time $(t+9 \Delta t)$. The central tendency values show high stability in the dispersion around the average. Figure 8 shows the observed number of vehicles in each cluster at each time interval $(\Delta t)$ in a normal traffic level. It gives a graphical representation to observe each cluster's stability in addition to the leaving or joining vehicles to each cluster during each successive $\Delta t$.

Table 5: Number of vehicles in each cluster at each time interval in normal traffic level

\begin{tabular}{|c|c|c|c|c|c|}
\hline & & & & \multicolumn{2}{|c|}{ Normal Traffic } \\
\hline Cluster number & Cluster 1 & Cluster 2 & Cluster 3 & Cluster 4 & Cluster 5 \\
\hline $\mathbf{t}$ & 8 & 13 & 16 & 19 & 27 \\
\hline $\mathbf{t}+\Delta \mathbf{t}$ & 8 & 13 & 16 & 19 & 28 \\
\hline$t+2 \Delta t$ & 8 & 13 & 15 & 19 & 28 \\
\hline$t+3 \Delta t$ & 8 & 13 & 15 & 20 & 29 \\
\hline$t+4 \Delta t$ & 9 & 14 & 15 & 20 & 28 \\
\hline$t+5 \Delta t$ & 10 & 14 & 15 & 20 & 28 \\
\hline$t+6 \Delta t$ & 10 & 14 & 15 & 20 & 29 \\
\hline$t+7 \Delta t$ & 10 & 14 & 15 & 20 & 29 \\
\hline$t+8 \Delta t$ & 10 & 14 & 16 & 19 & 29 \\
\hline $\mathbf{t}+9 \Delta t$ & 10 & 14 & 16 & 19 & 29 \\
\hline Average & $9.1 \approx 9$ & $13.6 \approx 14$ & $15.4 \approx 15$ & $19.5 \approx 20$ & $28.4 \approx 28$ \\
\hline $\begin{array}{l}\text { Standard } \\
\text { Deviation }\end{array}$ & 0.9 & 0.5 & 0.5 & 0.5 & 0.6 \\
\hline Range & 2 & 1 & 1 & 1 & 2 \\
\hline
\end{tabular}




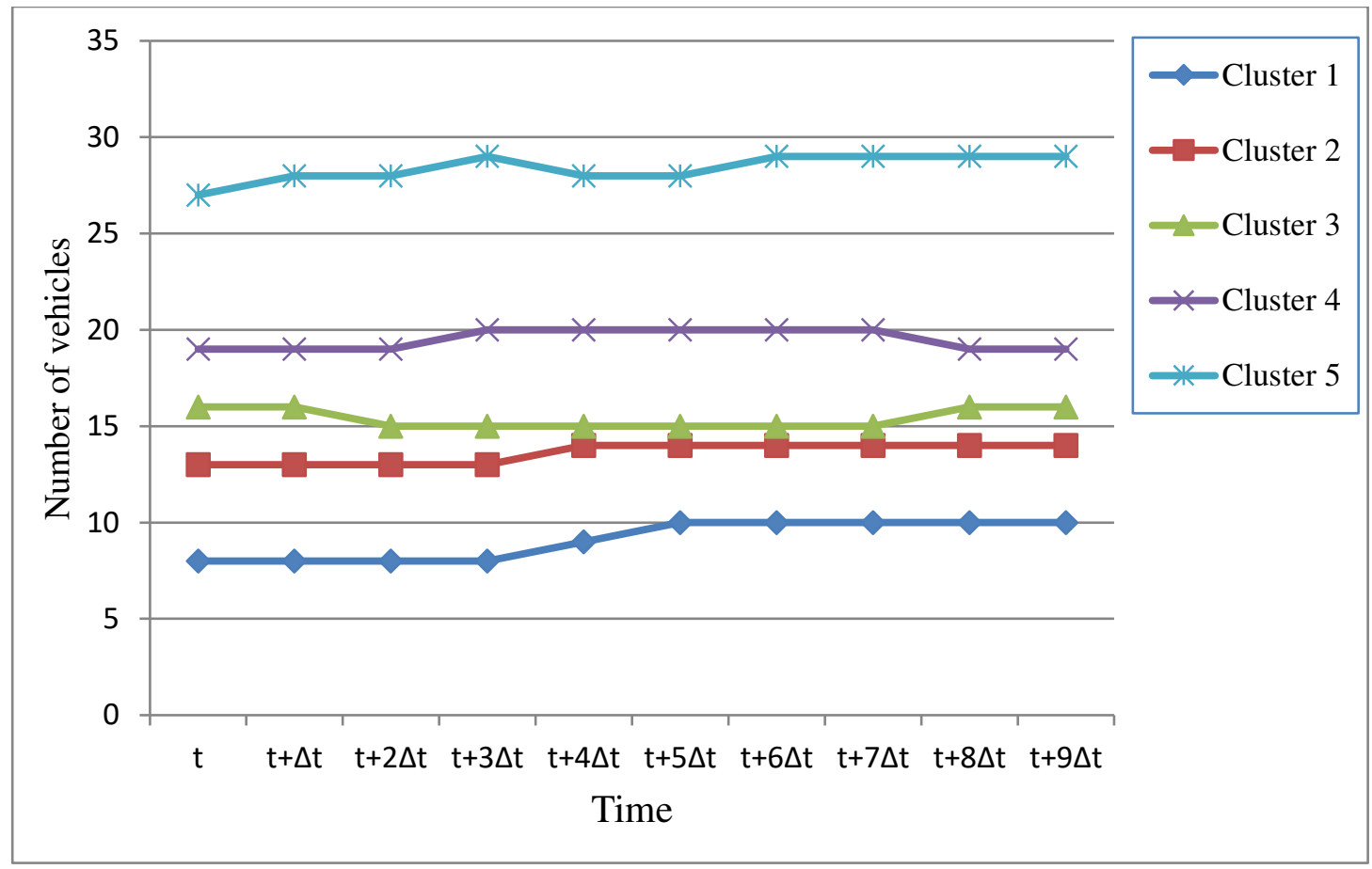

Figure 8: Number of vehicles in each cluster at each time interval for normal traffic level

Table 6 shows the observed number of vehicles in each cluster in a high traffic level during the time $\mathrm{t}$ to time $(\mathrm{t}+9 \Delta \mathrm{t})$. The central tendency measure values show high stability in the dispersion around the average for all clusters. Figure 9 shows a graphical representation to observe each cluster's stability and the leaving or joining vehicles to each cluster during each $\Delta t$. The results in this traffic level present the effect of high mobility concerning the other two levels. These results are observed through the range and the standard deviation values, although it keeps a high level of stability.

Table 6: Number of vehicles in each cluster at each time interval in high traffic level

\begin{tabular}{|c|c|c|c|c|c|}
\hline \multirow[b]{2}{*}{$\begin{array}{r}\text { Time/ } \\
\text { Cluster number }\end{array}$} & & & & \multicolumn{2}{|c|}{ High Traffic } \\
\hline & Cluster 1 & Cluster 2 & Cluster 3 & Cluster 4 & Cluster 5 \\
\hline $\mathbf{t}$ & 43 & 31 & 7 & 11 & 35 \\
\hline$t+\Delta t$ & 42 & 31 & 8 & 12 & 34 \\
\hline$t+2 \Delta t$ & 42 & 31 & 9 & 12 & 34 \\
\hline$t+3 \Delta t$ & 42 & 32 & 9 & 12 & 33 \\
\hline$t+4 \Delta t$ & 41 & 32 & 8 & 12 & 33 \\
\hline$t+5 \Delta t$ & 41 & 33 & 8 & 11 & 32 \\
\hline
\end{tabular}




$\begin{array}{rrrrrrr}\mathbf{t}+\mathbf{6} \Delta \mathbf{t} & 42 & 34 & 8 & 12 & 31 \\ \mathbf{t}+\mathbf{7} \Delta \mathbf{t} & 43 & 35 & 8 & 12 & 31 \\ \mathbf{t}+\mathbf{8 \Delta t} & 43 & 35 & 8 & 12 & 31 \\ \mathbf{t}+9 \Delta \mathrm{t} & 43 & 35 & 8 & 12 & 31 \\ \text { Average } & 42.2 \approx 42 & 32.9 \approx 33 & 8.1 \approx 8 & 11.8 \approx 12 & 32.5 \approx 33 \\ \text { Standard Deviation } & 0.7 & 1.7 & 0.5 & 0.4 & 1.5 \\ \text { Range } & 2 & 4 & 1 & 1 & 4\end{array}$

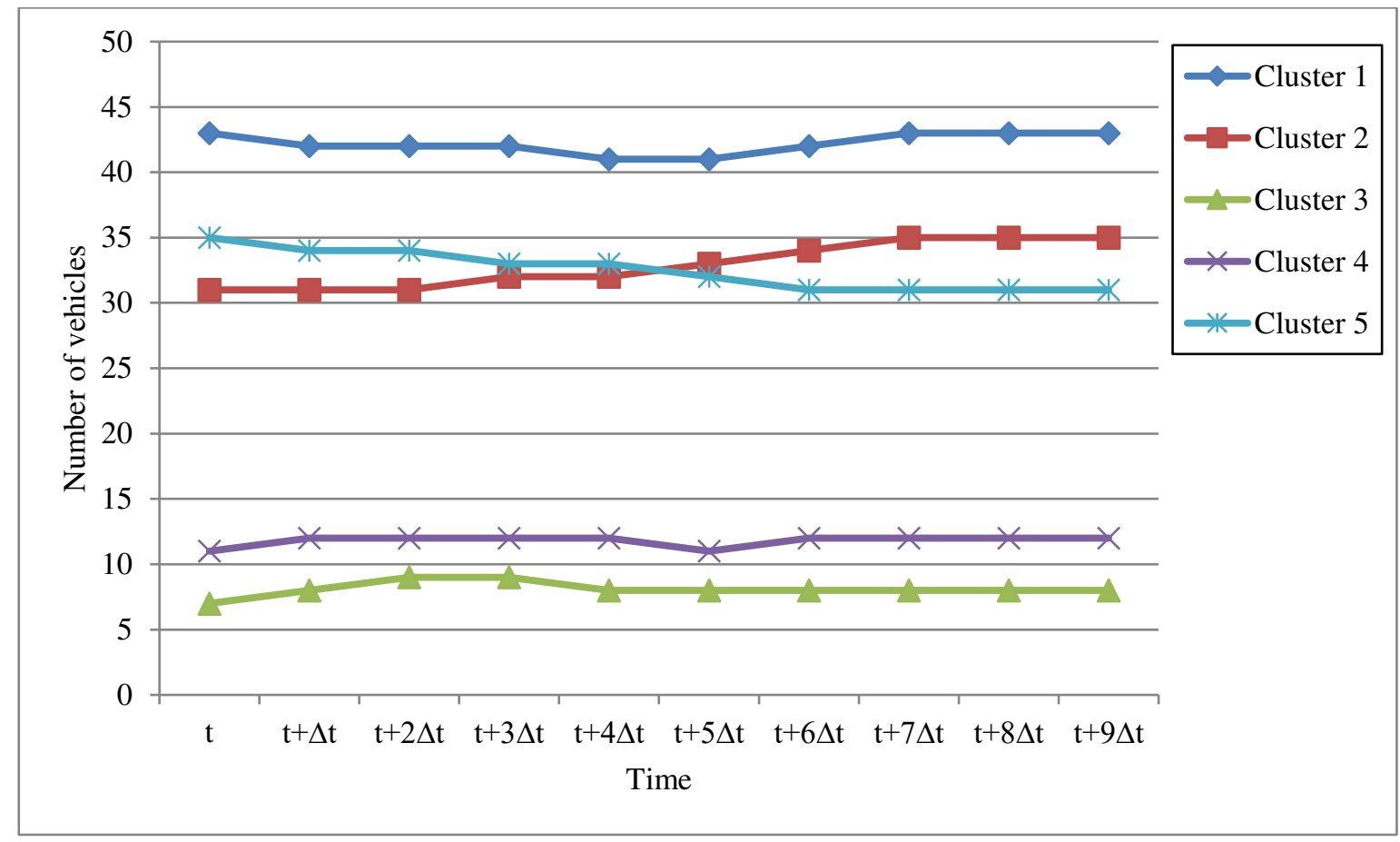

Figure 9: Number of vehicles in each cluster at each time interval for high traffic level

\section{Conclusions}

VANET represents one of the essential parts of ITS. Clustering was considered a critical part of the hierarchy of intelligent transportation systems. VANET clustering is the process of joining the neighboring moving vehicles on the road in one group according to specific properties. The critical aim of collecting the vehicles into groups (clusters) is to achieve higher connectivity, reducing the possible interruptions due to vehicles' random speeds. VANET clustering is to change the vehicle's network representation into sets of connected vehicles. A stable cluster is essential to support the routing and data dissemination process in a VANET. This study 
developed a mathematical technique (based on the birth-death process) to evaluate the clusters stability based on the number of leaving and joining vehicles to each cluster after its creation. The leaving and joining vehicles to each cluster after its establishment can be observed. In this study, the concept of this developed technique is implemented to test the stability of the cluster. This technique is used to test the cluster stability by observing the number of vehicles in each cluster at different successive times. In clustering approaches the leaving and joining vehicles to each cluster after its establishment can be expected without the completion of the environment experiment will be the future work.

\section{Acknowledgments}

The authors would like to thank the FTMK, and UTeM Zamalah-Scheme.

\section{Declarations}

*Funding (information that explains whether and by whom the research was supported): No funding was received.

*Conflicts of interest/Competing interests (include appropriate disclosures): No conflict of interest.

*Availability of data and material (data transparency): 'Not applicable'.

*Code availability (software application or custom code): 'Not applicable'.

*Authors' contributions (optional: please review the submission guidelines from the journal whether statements are mandatory): All authors contributed to this manuscript.

\section{References}

[1] G. F. Savari, V. Krishnasamy, J. Sathik, Z. M. Ali, and S. H. E. Abdel Aleem, "Internet of Things based real-time electric vehicle load forecasting and charging station recommendation," ISA Trans., vol. 97, pp. 431-447, 2020.

[2] D. Kombate and Wanglina, "The Internet of Vehicles Based on 5G Communications," in 2016 IEEE International Conference on Internet of Things (iThings) and IEEE Green Computing and Communications (GreenCom) and IEEE Cyber, Physical and Social Computing (CPSCom) and IEEE Smart Data (SmartData), 2016, pp. 445-448.

[3] X. Zhao, S. Jing, F. Hui, R. Liu, and A. J. Khattak, "DSRC-based rear-end collision warning system - An error-component safety distance model and field test," Transp. Res. Part C Emerg. Technol., vol. 107, no. August, pp. 92-104, 2019.

[4] I. Ahmad, M. N. Rafidah, and R. Z. Muhammad, "LTE efficiency when used in traffic information systems : A stable interest aware clustering," Int. J. Commun. Syst., no. October, pp. 1-18, 2018.

[5] W. Balzano, A. Murano, and S. Stranieri, "Logic-based clustering approach for management and improvement of VANETs," J. High Speed Networks, vol. 23, no. 3, pp. 225-236, 2017.

[6] B. Ramakrishnan, M. Selvi, and R. B. Nishanth, "Efficiency measure of routing protocols in vehicular ad 
hoc network using freeway mobility model," Wirel. Networks, vol. 23, no. 2, pp. 323-333, 2017.

[7] O. Senouci, S. Harous, and Z. Aliouat, "Survey on vehicular ad hoc networks clustering algorithms: Overview, taxonomy, challenges, and open research issues," Int. J. Commun. Syst., vol. 33, no. 11, pp. 1-21, 2020.

[8] H. W. Tseng, R. Y. Wu, and C. W. Lo, "A stable clustering algorithm using the traffic regularity of buses in urban VANET scenarios,” Wirel. Networks, vol. 26, no. 4, pp. 2665-2679, 2020.

[9] B. Hassanabadi, C. Shea, L. Zhang, and S. Valaee, "Clustering in Vehicular Ad Hoc Networks using Affinity Propagation,” Ad Hoc Networks, vol. 13, Part B, pp. 535-548, Feb. 2014.

[10] Y. Chen, M. Fang, S. Shi, W. Guo, and X. Zheng, "Distributed multi-hop clustering algorithm for VANETs based on neighborhood follow," Eurasip J. Wirel. Commun. Netw., vol. 2015, no. 1, pp. 1-12, 2015.

[11] S. Ucar, S. C. Ergen, and O. Ozkasap, "Multihop-Cluster-Based IEEE 802.11p and LTE Hybrid Architecture for VANET Safety Message Dissemination," IEEE Trans. Veh. Technol., vol. 65, no. 4, pp. 2621-2636, 2016.

[12] M. Ren, L. Khoukhi, H. Labiod, J. Zhang, and V. Vèque, "A mobility-based scheme for dynamic clustering in vehicular ad-hoc networks (VANETs)," Veh. Commun., vol. 9, pp. 233-241, 2017.

[13] E. Souza, I. Nikolaidis, and P. Gburzynski, "A new Aggregate Local Mobility (ALM) clustering algorithm for VANETs," in IEEE International Conference on Communications, 2010, pp. 1-5.

[14] R. Ghosh and S. Basagni, "Mitigating the impact of node mobility on ad hoc clustering," Wirel. Commun. Mob. Comput., vol. 8, no. 3, pp. 295-308, 2008.

[15] I. Tal and G. M. Muntean, "User-oriented fuzzy logic-based clustering scheme for vehicular ad-hoc networks," in IEEE Vehicular Technology Conference, 2013, pp. 1-5.

[16] B. Subba, S. Biswas, and S. Karmakar, "A game theory based multi layered intrusion detection framework for VANET,” Futur. Gener. Comput. Syst., vol. 82, pp. 12-28, 2018.

[17] N. Maslekar, J. Mouzna, H. Labiod, M. Devisetty, and M. Pai, "Modified C-DRIVE: Clustering based on direction in vehicular environment," in IEEE Intelligent Vehicles Symposium, Proceedings, 2011, no. Iv, pp. 845-850.

[18] M. S. Almalag and M. C. Weigle, "Using traffic flow for cluster formation in vehicular ad-hoc networks," in IEEE Local Computer Network Conference, 2010, pp. 631-636.

[19] S. Kuklinski and G. Wolny, "Density Based Clustering algorithm for Vehicular Ad-Hoc Networks," Int. J. Internet Protoc. Technol., vol. 4, no. 3, pp. 149-157, 2009.

[20] S.-T. Cheng, G.-J. Horng, and C.-L. Chou, "Using Cellular Automata to Form Car Society in Vehicular Ad Hoc Networks," IEEE Trans. Intell. Transp. Syst., vol. 12, no. 4, pp. 1374-1384, 2011.

[21] G. Wolny, "Modified DMAC clustering algorithm for VANETs," in The 3rd Int. Conf. Systems and Networks Communications, ICSNC, 2008, pp. 268-273.

[22] M. M. Caballeros Morales, C. S. Hong, and Y. C. Bang, "An Adaptable mobility-aware clustering algorithm in vehicular networks," in APNOMS 2011 - 13th Asia-Pacific Network Operations and Management Symposium: Managing Clouds, Smart Networks and Services, Final Program, 2011, pp. 1-6.

[23] A. Daeinabi, A. Ghaffar, P. Rahbar, and A. Khademzadeh, "VWCA : An efficient clustering algorithm in vehicular ad hoc networks," J. Netw. Comput. Appl., vol. 34, no. 1, pp. 207-222, 2011.

[24] W. Li, A. Tizghadam, and A. Leon-Garcia, "Robust clustering for connected vehicles using local network 
criticality," in IEEE International Conference on Communications (ICC), 2012, 2012, pp. 7157-7161.

[25] A. Ahizoune and A. Hafid, "A new stability based clustering algorithm (SBCA) for VANETs," in Proceedings - Conference on Local Computer Networks, LCN, 2012, pp. 843-847.

[26] Z. Y. Rawashdeh and S. Mahmud, "A novel algorithm to form stable clusters in vehicular ad hoc networks on highways," EURASIP J. Wirel. Commun. Netw., vol. 2012, no. 1, p. 15, 2012.

[27] L. A. Maglaras and D. Katsaros, "Distributed clustering in vehicular networks," in International Conference on Wireless and Mobile Computing, Networking and Communications, 2012, pp. 593-599.

[28] K. A. Hafeez, L. Zhao, Z. Liao, and B. N. W. Ma, "A fuzzy-logic-based cluster head selection algorithm in VANETs," in IEEE International Conference on Communications, 2012, pp. 203-207.

[29] F. Chiti, R. Fantacci, and G. Rigazzi, "A mobility driven joint clustering and relay selection for IEEE 802.11p/WAVE vehicular networks," in 2014 IEEE International Conference on Communications, ICC 2014, 2014, pp. 348-353.

[30] X. Cheng, B. Huang, and W. Cheng, "Stable clustering for VANETs on highways," in Third ACM/IEEE Symposium on Edge Computing, SEC, 2018, pp. 399-403.

[31] M. Ren, J. Zhang, L. Khoukhi, H. Labiod, and V. Veque, "A Unified Framework of Clustering Approach in Vehicular Ad Hoc Networks,” IEEE Trans. Intell. Transp. Syst., vol. 19, no. 5, pp. 1401-1414, May 2018.

[32] X. Cheng and B. Huang, "A Center-Based Secure and Stable Clustering Algorithm for VANETs on Highways,” Wirel. Commun. Mob. Comput., vol. 2019, no. Article ID 8415234, pp. 1-10, 2019.

[33] H. Alabbas and Á. Huszák, "A New Clustering Algorithm for Live Road Surveillance on Highways based on DBSCAN and Fuzzy Logic," Int. J. Adv. Comput. Sci. Appl., vol. 11, no. 8, pp. 580-587, 2020.

[34] M. S. Talib, A. Hassan, B. Hussin, Z. A. Abas, Z. S. Talib, and Z. S. Rasoul, "A Novel Stable Clustering Approach based on Gaussian Distribution and Relative Velocity in VANETs," IJACSA) Int. J. Adv. Comput. Sci. Appl., vol. 9, no. 4, pp. 216-220, 2018.

[35] M. S. Talib et al., "A Center-based Stable Evolving Clustering Algorithm with Grid Partitioning and Extended Mobility Features for VANETs," IEEE Access, vol. 8, pp. 169908-169921, 2020. 


\section{Figures}

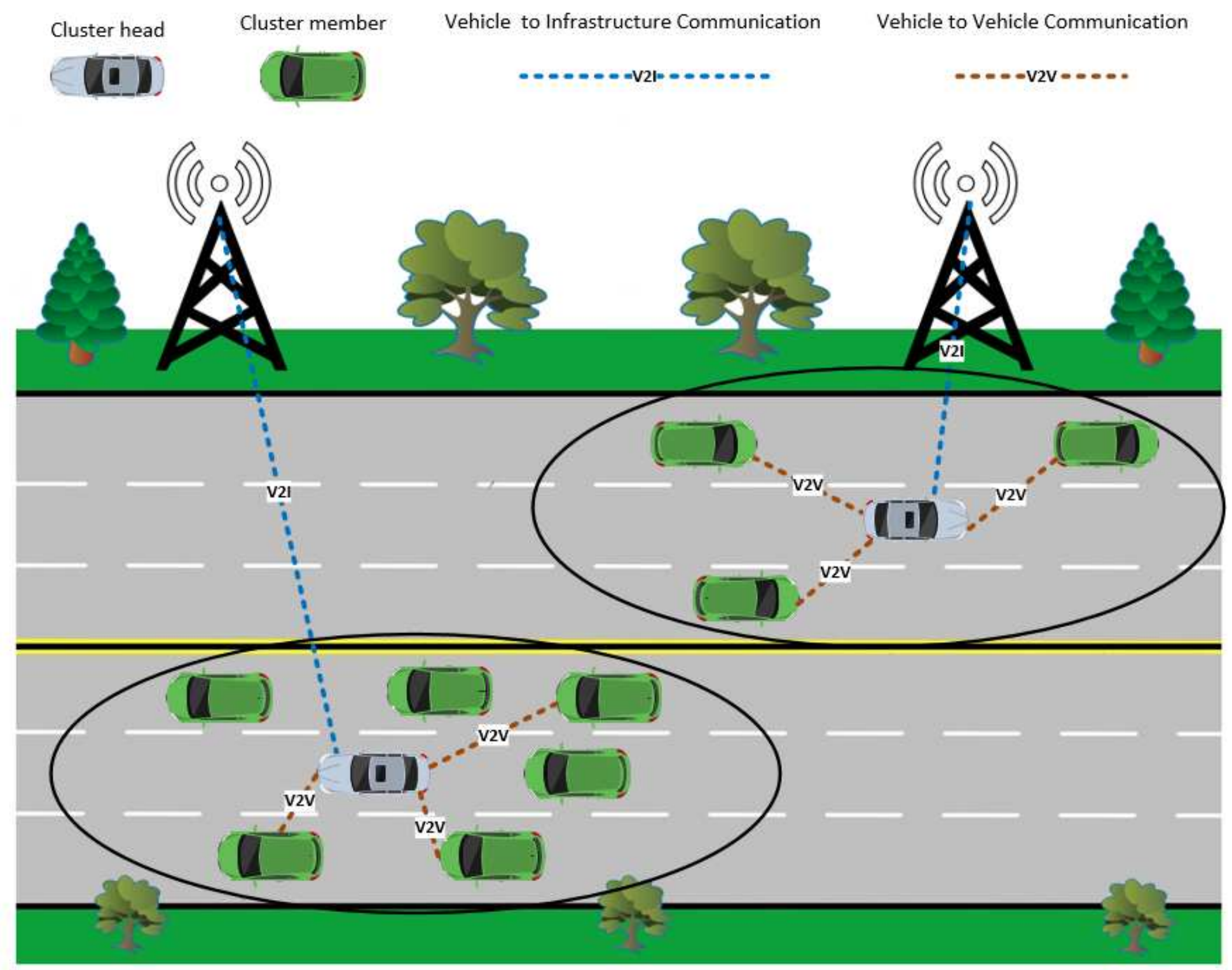

Figure 1

Clustering in vehicular ad hoc networks 


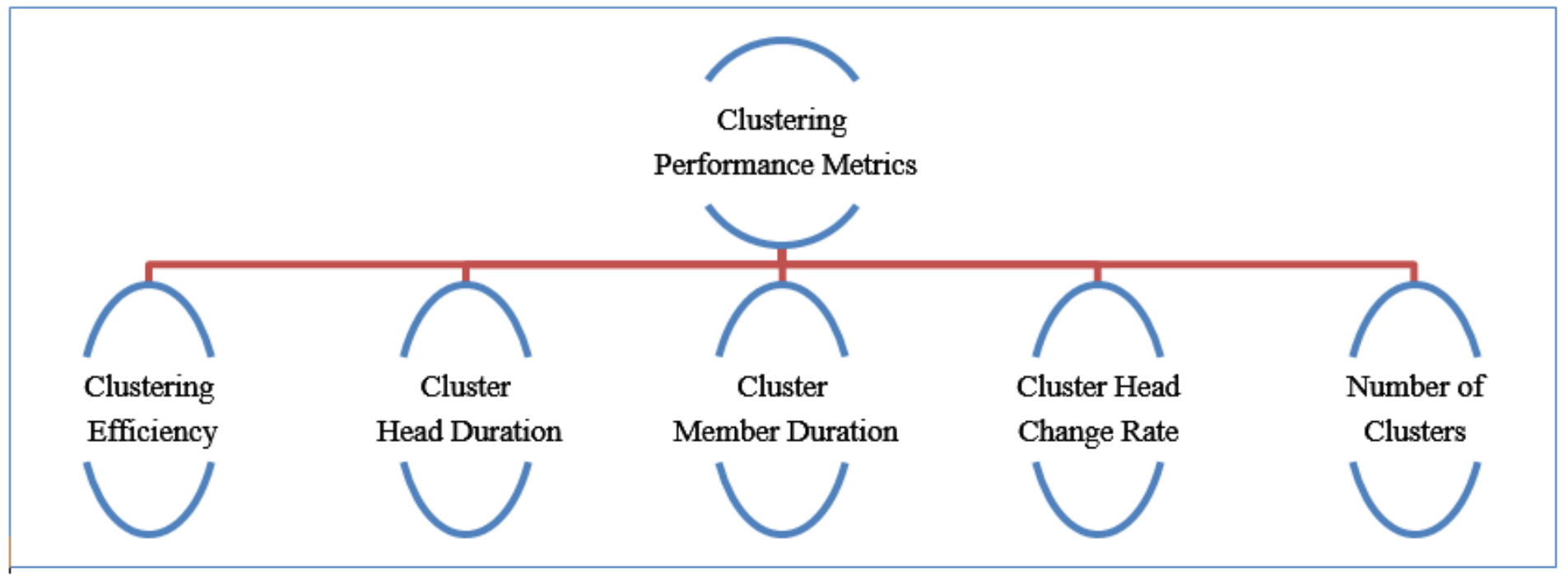

Figure 2

Performance metrics of clustering stability 


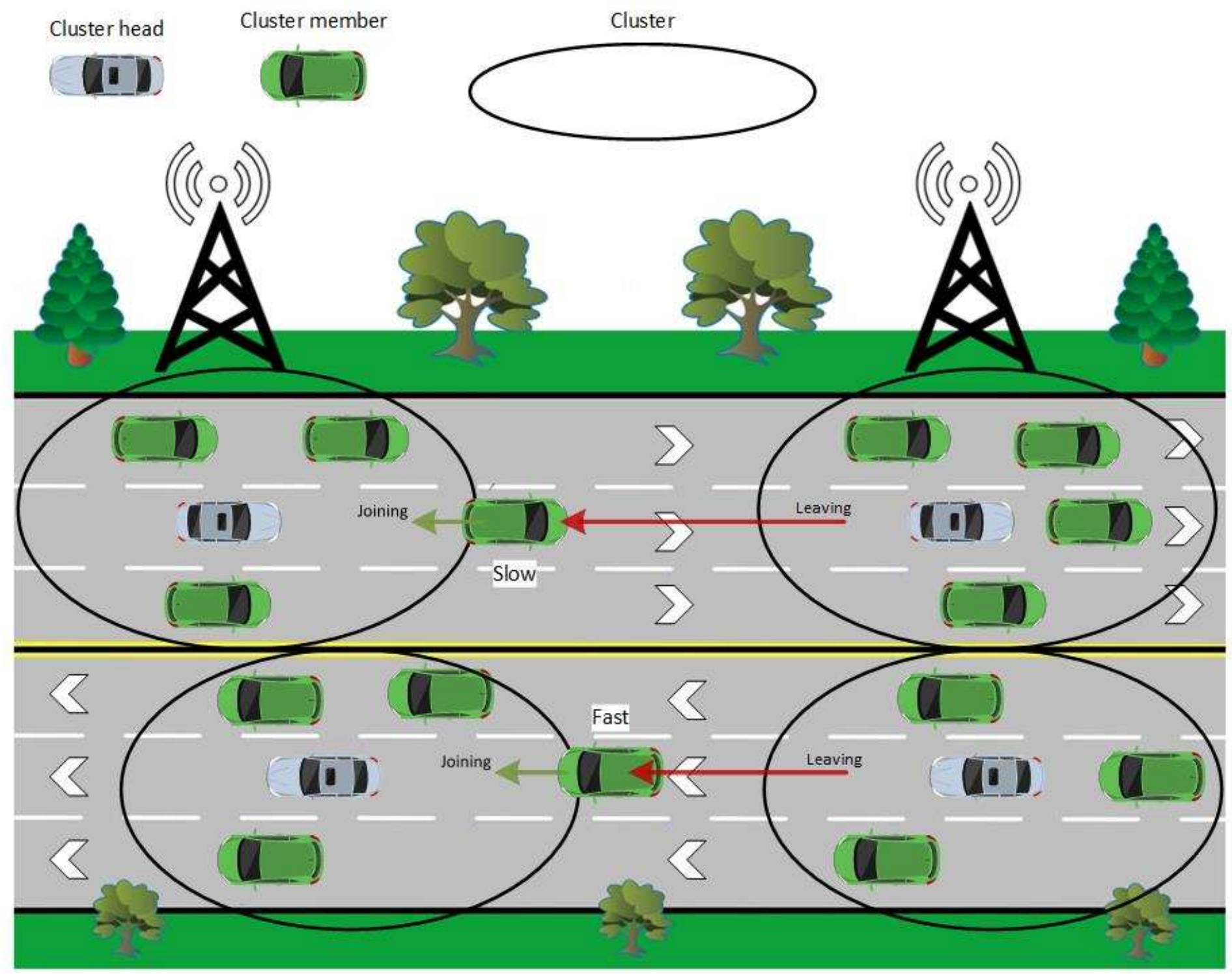

Figure 3

Vehicles leaving and joining representation 


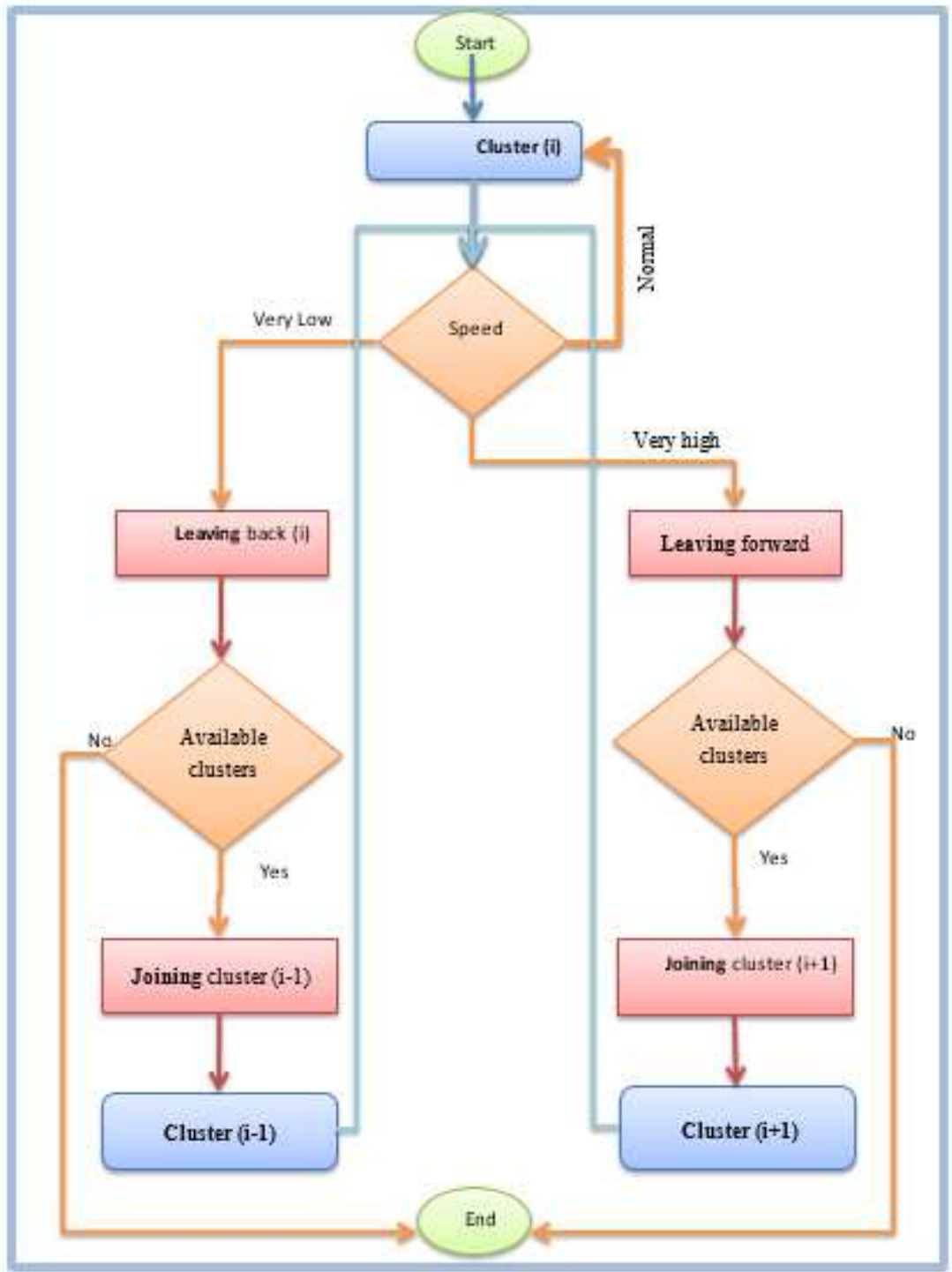

Figure 4

Flowchart for vehicles leaving and joining from/to a cluster 


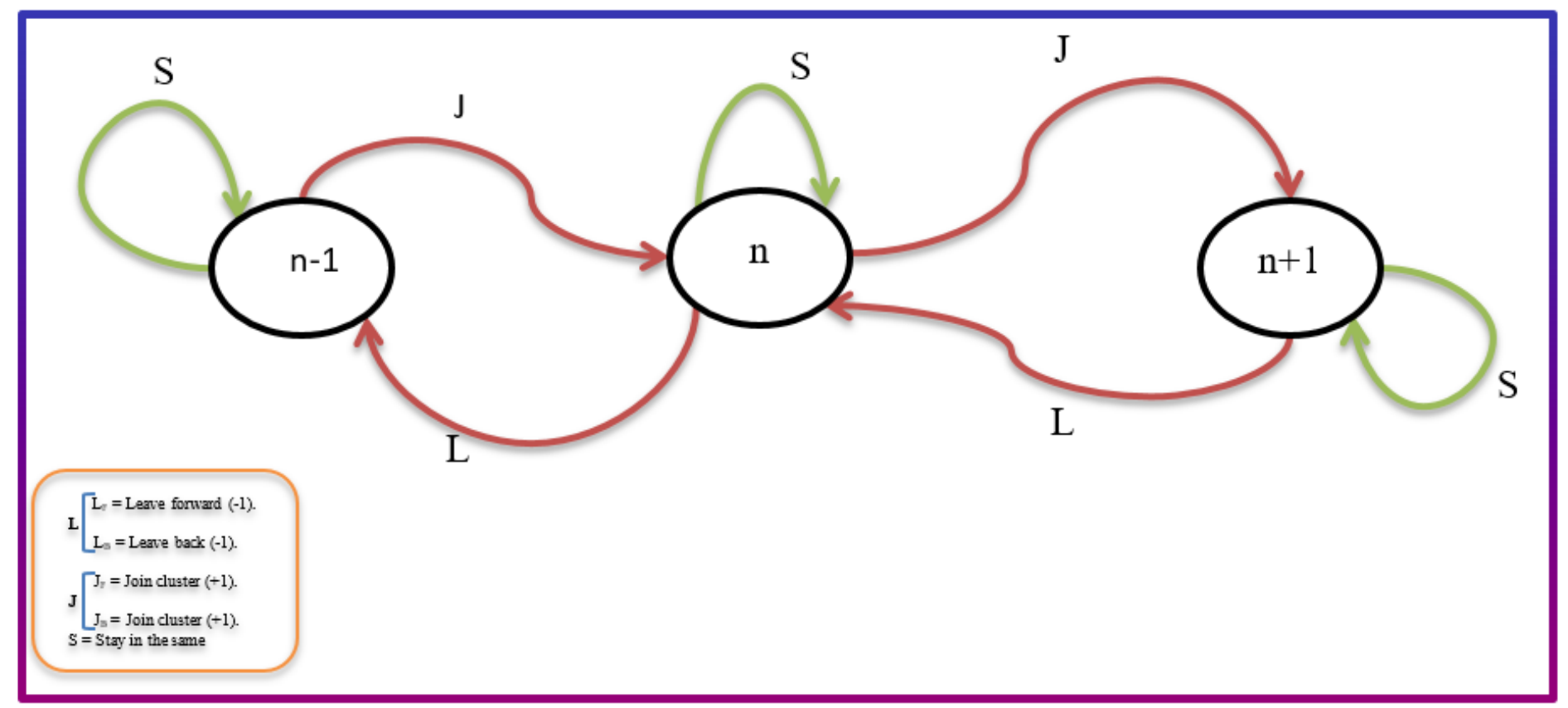

Figure 5

State diagram for vehicles leaving and joining process

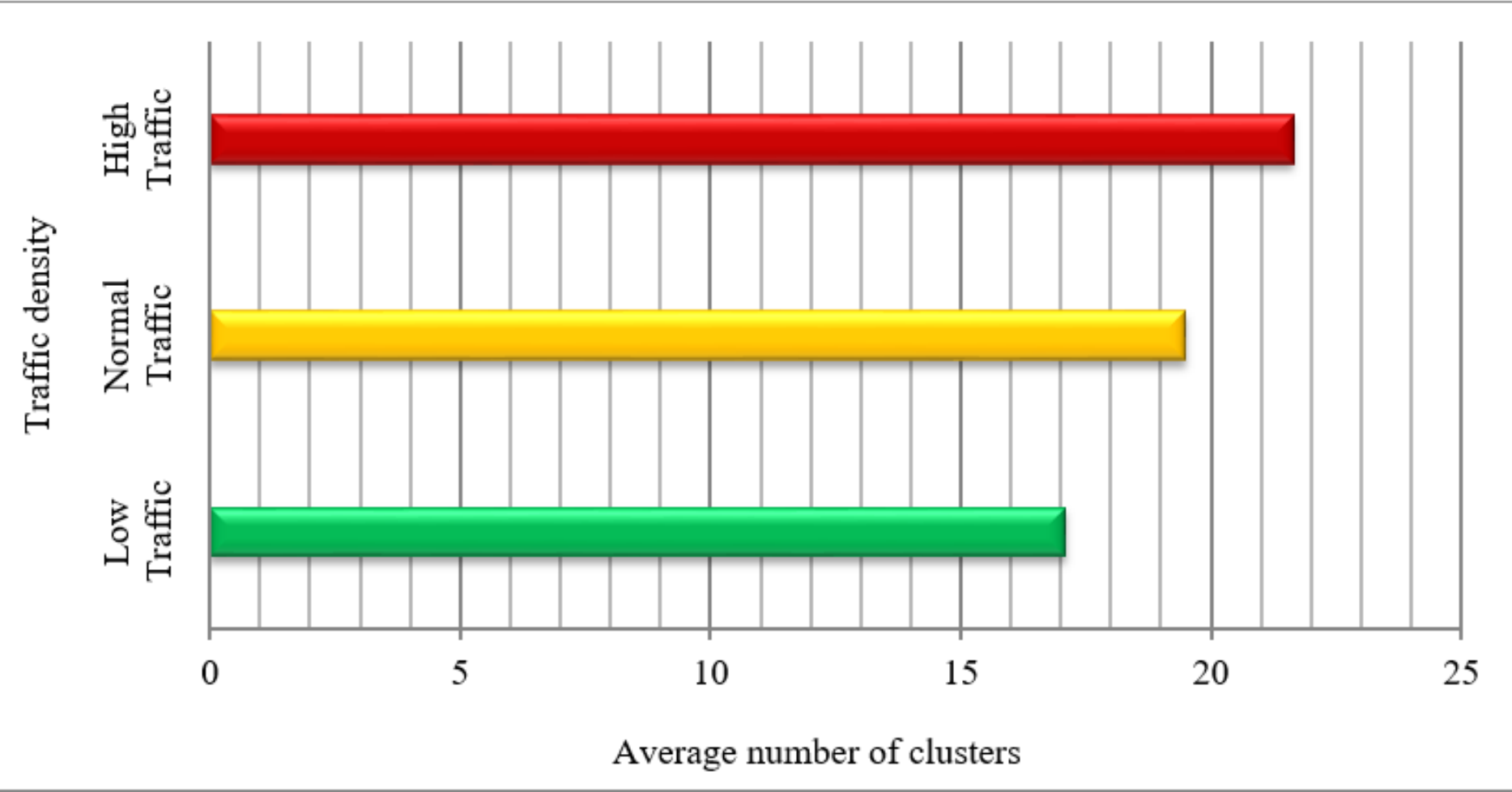

Figure 6

The average number of clusters in CEC-GP 


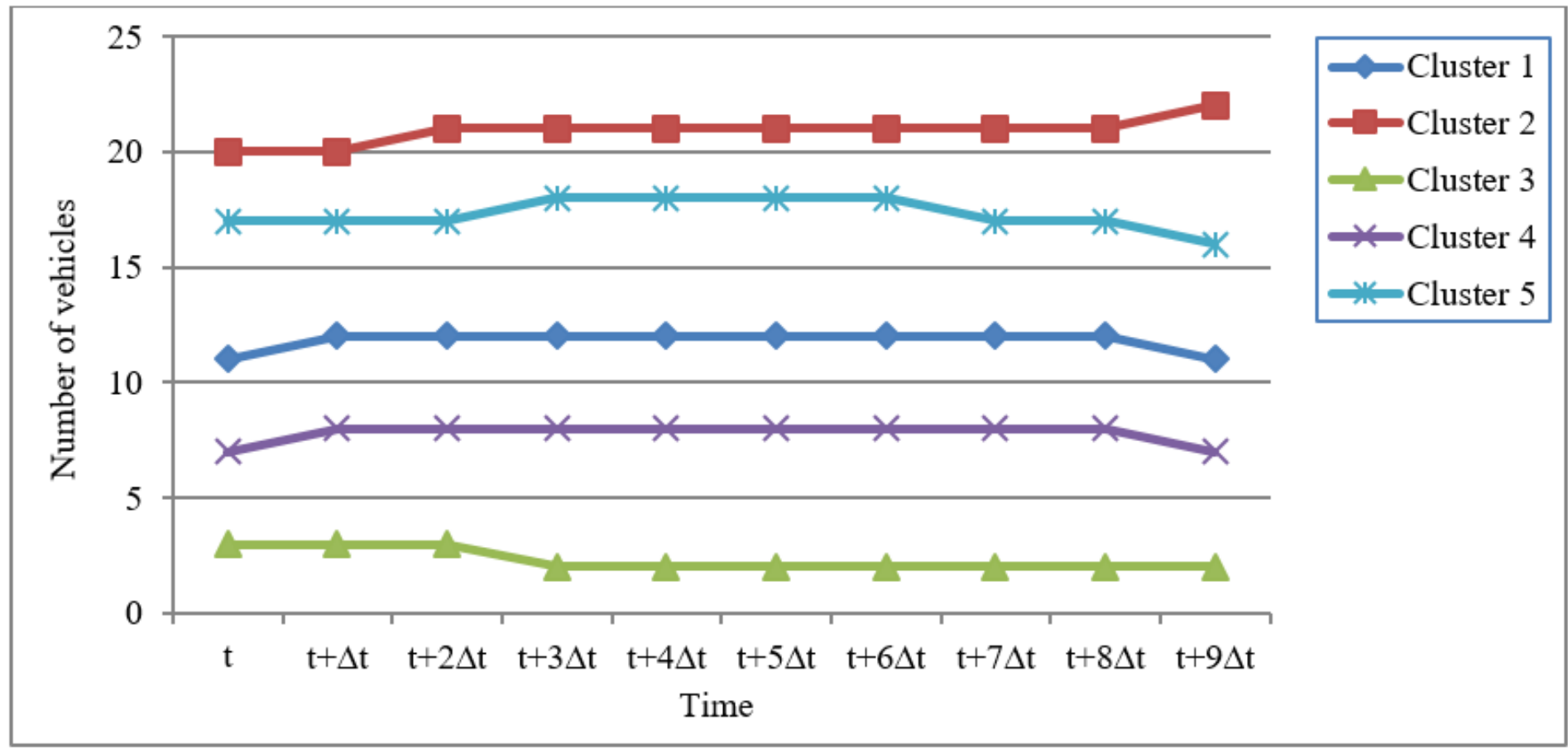

Figure 7

Number of vehicles in each cluster at each time interval for the low traffic level

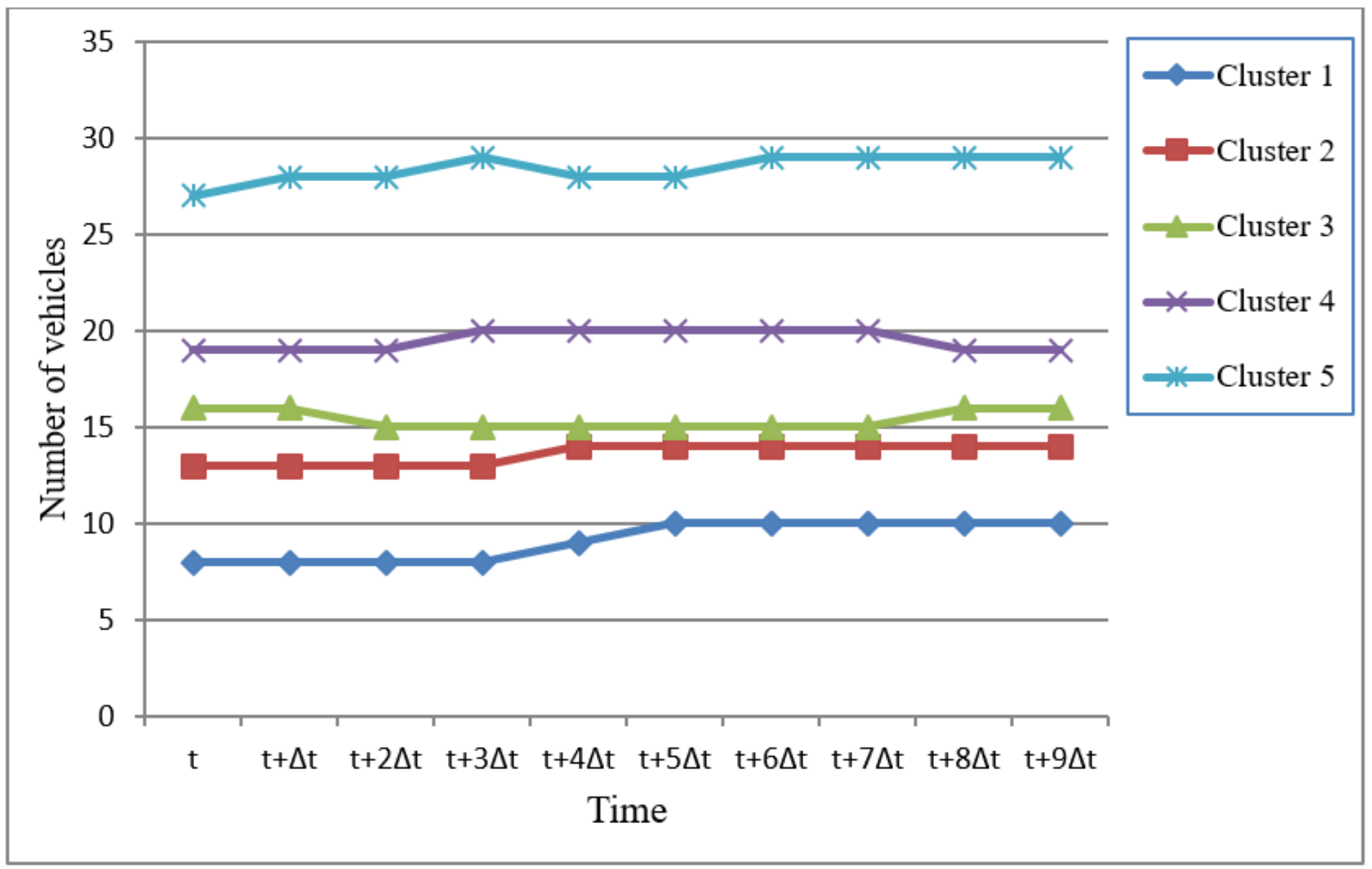


Number of vehicles in each cluster at each time interval for normal traffic level 